\title{
Overexpression of the Astrocyte Glutamate Transporter GLT1 Exacerbates Phrenic Motor Neuron Degeneration, Diaphragm Compromise, and Forelimb Motor Dysfunction following Cervical Contusion Spinal Cord Injury
}

\author{
Ke Li, ${ }^{1 \star}$ Charles Nicaise, ${ }^{1,2 *}$ Daniel Sannie, ${ }^{1}$ (D) Tamara J. Hala, ${ }^{1}$ Elham Javed, ${ }^{1}$ Jessica L. Parker, ${ }^{1}$ \\ Rajarshi Putatunda, ${ }^{1}$ Kathleen A. Regan, ${ }^{1}$ Valérie Suain, ${ }^{3}$ Jean-Pierre Brion, ${ }^{3}$ Fred Rhoderick, ${ }^{4}$ Megan C. Wright, ${ }^{5}$ \\ David J. Poulsen, ${ }^{4}$ and Angelo C. Lepore ${ }^{1}$ \\ 'Department of Neuroscience, Farber Institute for Neurosciences, Thomas Jefferson University Medical College, Philadelphia, Pennsylvania 19107, \\ ${ }^{2}$ Neurodegeneration and Regeneration Unit, L’Unité de Recherché en Physiologie Moléculaire-Namur Research Institute for Life Sciences, University of \\ Namur, B-5000 Namur, Belgium, ${ }^{3}$ Laboratory of Histology, Neuroanatomy and Neuropathology, Université Libre de Bruxelles, B-1070 Brussels, Belgium, \\ ${ }^{4}$ Department of Biomedical and Pharmaceutical Sciences, University of Montana, Missoula, Montana 59812, and 5epartment of Biology, Arcadia \\ University, Glenside, Pennsylvania 19038
}

\begin{abstract}
A major portion of spinal cord injury (SCI) cases affect midcervical levels, the location of the phrenic motor neuron (PhMN) pool that innervates the diaphragm. While initial trauma is uncontrollable, a valuable opportunity exists in the hours to days following SCI for preventing PhMN loss and consequent respiratory dysfunction that occurs during secondary degeneration. One of the primary causes of secondary injury is excitotoxic cell death due to dysregulation of extracellular glutamate homeostasis. GLT1, mainly expressed by astrocytes, is responsible for the vast majority of functional uptake of extracellular glutamate in the CNS, particularly in spinal cord. We found that, in bacterial artificial chromosome-GLT1-enhanced green fluorescent protein reporter mice following unilateral midcervical (C4) contusion SCI, numbers of GLT1-expressing astrocytes in ventral horn and total intraspinal GLT1 protein expression were reduced soon after injury and the decrease persisted for $\geq 6$ weeks. We used intraspinal delivery of adeno-associated virus type 8 (AAV8)-Gfa2 vector to rat cervical spinal cord ventral horn for targeting focal astrocyte GLT1 overexpression in areas of PhMN loss. Intraspinal delivery of AAV8-Gfa2-GLT1 resulted in transduction primarily of GFAP ${ }^{+}$astrocytes that persisted for $\geq 6$ weeks postinjury, as well as increased intraspinal GLT1 protein expression. Surprisingly, we found that astrocyte-targeted GLT1 overexpression increased lesion size, PhMN loss, phrenic nerve axonal degeneration, and diaphragm neuromuscular junction denervation, and resulted in reduced functional diaphragm innervation as assessed by phrenic nerve-diaphragm compound muscle action potential recordings. These results demonstrate that GLT1 overexpression via intraspinal AAV-Gfa2-GLT1 delivery exacerbates neuronal damage and increases respiratory impairment following cervical SCI.
\end{abstract}

Key words: adeno-associated virus; gene therapy; glutamate transporter; phrenic motor neuron; respiratory; spinal cord injury

\section{Introduction}

Cervical spinal cord trauma represents greater than half of all human spinal cord injury (SCI) cases, in addition to often result-

Received Oct. 25, 2013; revised April 1, 2014; accepted April 23, 2014.

Author contributions: K.L., C.N., J.L.P., M.C.W., D.J.P., and A.C.L. designed research; K.L., C.N., D.S., T.J.H., E.J., J.L.P., R.P., K.A.R., V.S., J.-P.B., F.R., M.C.W., D.J.P., and A.C.L. performed research; K.L., C.N., D.S., T.J.H., E.J., J.L.P., R.P., K.A.R., M.C.W., and A.C.L. analyzed data; K.L., C.N., and A.C.L. wrote the paper.

This work was supported by the Université Libre de Bruxelles (Bureau des Relations Internationales et de la Cooperation, Grant BRIC-11/092 to C.N.), the Morton Cure Paralysis Fund (to A.C.L.), the Craig H. Neilsen Foundation (Grant \#190140 to A.C.L.), and the National Institute of Neurological Disorders and Stroke (Grant \#1R01NS079702 to A.C.L.). We thank Bruno Couturier and Fabrice Gankam-Kengné for critically reviewing the manuscript.

The authors declare no competing financial interests.

*K.L. and C.N. contributed equally to this work.

Correspondence should be addressed to Angelo C. Lepore, PhD, Department of Neuroscience, Farber Institute for Neurosciences, Thomas Jefferson University Medical College, 900 Walnut Street, JHN 469, Philadelphia, PA 19107. E-mail: Angelo.Lepore@jefferson.edu. ing in especially severe physical and psychological debilitation. Chronic respiratory compromise is the leading cause of morbidity and mortality following cervical SCI, and is due to phrenic motor neuron (PhMN) loss and/or injury to descending bulbospinal respiratory axons (Lane et al., 2008). The major inspiratory muscle, the diaphragm, is innervated by PhMNs located at midcervical levels C3-C5. Importantly, the majority of these injuries affect the location of the PhMN pool, and respiratory function following midcervical SCI is significantly determined by PhMN loss/sparing (Strakowski et al., 2007).

Contusion-type trauma, the predominant form of SCI observed in the clinical population, is followed by a period of sec- 
ondary cell death and consequent exacerbation of functional deficits (Oyinbo, 2011). Glutamate-mediated excitotoxicity plays a key role in these secondary events. Large increases in extracellular glutamate occur shortly after SCI, and elevation can also persist, depending on injury severity (Panter et al., 1990; Liu et al., 1991; McAdoo et al., 1999). Early gray matter loss is likely mediated by NMDA receptors, while delayed loss of neurons and oligodendrocytes, as well as axonal and myelin injury, is thought to be predominantly mediated via AMPA overactivation. Spinal motor neurons are particularly vulnerable to glutamate excitotoxicity due to such factors as expression of calcium-permeable glutamate receptors and low calcium-buffering capacities (Xu et al., 2004, 2008).

Glutamate transporter-1 (GLT1) plays a central role in regulating extracellular glutamate levels. GLT1 is almost exclusively expressed by astrocytes and accounts for $\sim 90 \%$ of functional uptake of extracellular glutamate (Tanaka et al., 1997). Following SCI, astrocyte death, and/or compromised GLT1 expression, membrane localization and/or function can result in dysregulation of glutamate homeostasis. Several studies have shown that GLT1 expression is chronically reduced following thoracic SCI (Kim et al., 2011; Min et al., 2012). Changes in GLT1 expression appear to be spatiotemporally regulated in a more subtle manner (Xu et al., 2008; Gwak et al., 2012). Rapid GLT1 upregulation has been reported within the first hours post-SCI (Vera-Portocarrero et al., 2002) in surviving astrocytes (Xu et al., 2008). This increase may function to counteract immediate elevation of glutamate during the early phase; however, this initial response is followed by long-lasting downregulation due to astrocyte death and reduced expression in reactive astrocytes and even in newly generated cells arising from astrocyte proliferation (Xu et al., 2008; Min et al., 2012). These data suggest that the long-term ability of astrocytes to regulate extracellular glutamate homeostasis post$\mathrm{SCI}$ is compromised, which increases susceptibility to secondary excitotoxic damage.

Selective GLT1 overexpression in adult astrocytes had previously made it difficult to clearly determine its exact contribution to neuroprotection following SCI. To this end, we used recombinant adeno-associated viral type 8 (AAV8) vectors to selectively drive overexpression of GLT1 in astrocytes in a clinically relevant model of midcervical contusion SCI. Furthermore, we evaluated key histological and functional outcomes associated with a large proportion of human SCI, namely PhMN loss, diaphragm denervation, and consequent respiratory dysfunction.

\section{Materials and Methods}

\section{Animals}

Transgenic bacterial artificial chromosome (BAC)-GLT1-enhanced green fluorescent protein (eGFP) transgenic mice were previously generated by Regan et al. (2007) and were a kind gift from Jeffrey Rothstein's laboratory at Johns Hopkins University. BAC-GLT1-eGFP mice were used to quantify GLT1 promoter activity following cervical contusion. Male BAC-GLT1-eGFP mice and wild-type C57BL/6 mice aged from 8 to 12 weeks were used in the study. Female Sprague Dawley rats weighing 250-300 g were purchased from Taconic Farm. Rats were divided into three paradigm groups according to the experimental design described below. All animals were housed in a humidity-controlled, temperaturecontrolled, and light-controlled animal facility under standard chow and with ad libitum access to water. Experimental procedures were approved by the Thomas Jefferson University institutional animal care and use committee and conducted in compliance with the European Communities Council Directive (2010/63/EU, 86/609/EEC, and 87-848/EEC), the National Institutes of Health Guide for the Care and Use of Laboratory Animals, and the Society for Neuroscience's Policies on the Use of Animals in Neuroscience Research.

\section{Experimental design}

Mouse SCI paradigm. BAC-GLT1-eGFP mice were subjected to cervical contusion SCI at both C4 and C5 levels (Nicaise et al., 2012b), and were then killed 2, 14, or $42 \mathrm{~d}$ postinjury (DPI). Spinal cord tissue was processed for histology to quantify the number of eGFP ${ }^{+}$cells in the ventral horn ipsilateral to the lesion site. Nontransgenic C57BL/6 mice also received $\mathrm{C} 4+\mathrm{C} 5$ spinal contusion to measure whole-tissue GLT1 protein levels by immunoblotting. After the animal was killed, the spinal cord was freshly removed, subdivided into 1.5-mm-long hemicord fragments encompassing the epicenter of the injury or spinal cord segments caudal to the epicenter (Fig. 1C), and then snap-frozen with liquid nitrogen.

Rat SCI paradigm 1. AAV-Gfa2-eGFP or AAV-Gfa2-GLT1 was injected into the spinal cord ventral horn of sham (laminectomy-only uninjured) or spinally contused rats, and rats were then killed 2 or $10 \mathrm{~d}$ postinjection. This preliminary study was used to determine the efficiency of the virus for targeting/transducing spinal cord astrocytes, the timing of GLT1 overexpression, and the spatial distribution/spread of virus transduction.

Rat SCI paradigm 2. AAV-Gfa2-eGFP or AAV-Gfa2-GLT1 was injected into the spinal cord ventral horn at the C3, C4, and C5 levels ipsilateral to the injury site (see Fig. 3A) $10 \mathrm{~d}$ before unilateral C4 contusion (see Fig. 5A). Rats were killed 42 DPI. This "pretreatment" paradigm was aimed at boosting the levels of GLT1 within the spinal cord before injury as proof of principle. These animals were used for comprehensive behavioral, electrophysiological, and histological analysis of the therapeutic efficacy of GLT1 overexpression.

Rat SCI paradigm 3. Rats were injured at the C4 level and were then immediately injected with AAV-Gfa2-eGFP or AAV-Gfa2-GLT1 into spinal cord ventral horn at the $\mathrm{C} 3, \mathrm{C} 4$, and $\mathrm{C} 5$ levels ipsilateral to the injury site (see Figs. 3A, $8 A$ ). This "acute" AAV injection was tested as a more clinically relevant paradigm of AAV-mediated GLT1 overexpression.

\section{Cervical contusion SCI}

Cervical contusion SCI was performed on mice and rats. Mice were anesthetized with ketamine $(120 \mathrm{mg} / \mathrm{kg})$ and xylazine $(5 \mathrm{mg} / \mathrm{kg})$. The dorsal skin and underlying muscle layers were incised and retracted between the spinous processes of $\mathrm{C} 2$ and $\mathrm{T} 1$. The paravertebral muscles overlying $\mathrm{C} 4-\mathrm{C} 6$ were removed. Following right-sided unilateral laminectomy at $\mathrm{C} 4$ and $\mathrm{C} 5$ levels, mice were subjected to a double spinal contusion injury with the Infinite Horizon impactor (Precision Systems and Instrumentation) at both $\mathrm{C} 4$ and $\mathrm{C} 5$ levels using a $1 \mathrm{~mm}$ tip. The force of both impacts was $50 \mathrm{kdyn}$ (impact on C4 was generated first). Sham control mice underwent the same surgery, including laminectomy, but did not receive contusion injury. Rats were anesthetized with ketamine $(100 \mathrm{mg} / \mathrm{kg})$, xylazine $(5 \mathrm{mg} / \mathrm{kg})$, and acepromazine $(2 \mathrm{mg} / \mathrm{kg})$. The cervical dorsal skin and underlying muscles were incised. The paravertebral muscles overlying $\mathrm{C} 3-\mathrm{C} 5$ were removed. Following unilateral laminectomy on the right side at $\mathrm{C} 3, \mathrm{C} 4$, and $\mathrm{C} 5$ levels, rats were subjected to a $\mathrm{C} 4$ spinal contusion injury with the Infinite Horizon impactor using a $1.5 \mathrm{~mm}$ tip at a force of $395 \mathrm{kdyn}$. These injury paradigms are based on our previously published mouse (Nicaise et al., 2012b) and rat (Nicaise et al., 2012a, 2013) models that result in robust PhMN degeneration and chronic diaphragm dysfunction. After surgical procedures in both mice and rats, overlying muscles were closed in layers with sterile 4-0 silk sutures, and the skin incision was closed using wound clips. Animals were allowed to recover on a circulating warm-water heating pad until awake and then returned to their home cages. They were monitored daily until they were killed, and measures were taken to avoid dehydration and to minimize any pain or discomfort. No signs of bladder or bowel dysfunction were ever detected following injury.

\section{Virus production and delivery}

Two recombinant AAV8 vectors carrying eGFP or GLT1 driven by the Gfa2 promoter were constructed to specifically target astrocytes. The viral vectors were prepared as previously described (Weller et al., 2008). Recombinant AAV8 was packaged in HEK293T cells. Approximately $1.5 \times 10^{7}$ cells were seeded into $150 \mathrm{~cm}$ dishes in DMEM supplemented with 10\% FBS, $1 \mathrm{~mm}$ MEM sodium pyruvate, $0.1 \mathrm{~mm}$ MEM nonessential amino acids, and $0.05 \%$ penicillin-streptomycin $(5000 \mathrm{U} / \mathrm{ml})$. At $24 \mathrm{~h}$ 
after cell seeding, medium was changed to culture medium containing only 5\% FBS, and cells were transfected with three plasmids: adeno helper plasmid ( $\mathrm{pF} \Delta 6$ ), AAV helper encoding serotype 8 (kindly provided by Miguel Sene Esteves at the University of Massachusetts), and the AAV packaging vector containing the glial fibrillary acidic protein (GFAP) promoter flanked by either the eGFP gene or the human EAAT2 (GLT1a) gene sequence (obtained from Jeffrey Rothstein's laboratory). Plasmids were transfected into HEK293T cells using Polyfect according to the manufacturer's specifications (Qiagen). Cultures were incubated at $37^{\circ} \mathrm{C}$ in $95 \% \mathrm{O}_{2}$ and $5 \% \mathrm{CO}_{2}$. After $72 \mathrm{~h}$, cells were harvested and pelleted by centrifugation. The pellet was resuspended in 10 mм Tris, $\mathrm{pH} 8.0$, and chilled on ice. Cells were lysed by repeated freeze-thaw cycles, followed by treatment with $50 \mathrm{U}$ benzonase (Novagen) and $0.5 \%$ sodium deoxycholate for $30 \mathrm{~min}$ at $37^{\circ} \mathrm{C}$. The lysate was sonicated three times. Virus was then purified by density gradient centrifugation in iodixanol according to the method of Zolotukhin et al. (1999). Each virus preparation was sterile filtered, and the titer (genomic particles $/ \mathrm{ml}$ ) was determined by quantitative RT-PCR using primers and a probe specific for the woodchuck posttranscriptional regulatory element sequence.

Virus delivery was conducted on deeply anesthetized rats. Following unilateral rightsided laminectomy, three injections, each containing $1 \mu \mathrm{l}$ of virus (titer of $10^{13}$ genomic particles $/ \mathrm{ml}$ ), were administered in the spinal cord ventral horn at levels C3, C4, and C5 using a Hamilton gas-tight syringe mounted on an electronic UMP3 micropump (World Precision International; Lepore and Maragakis, 2011; Lepore, 2011). As shown in Figure 3A, the sites of injections were targeted along the rostral-caudal axis with a virtual line connecting the points of dorsal root entry (dotted line) and in the lateral axis corresponding to the middle of each spinal segment (C3, C4, or C5). Ventral horns were targeted by lowering the 33 gauge $45^{\circ}$ beveled needle $1.5 \mathrm{~mm}$ below the dorsal surface of the spinal cord. Each injection was delivered at a constant rate over $5 \mathrm{~min}$. Upon completion of virus delivery, a synthetic biocompatible membrane (BioBrane, UDL Laboratories) was placed on the top of laminectomy, which allowed for easy access to the spinal cord below the laminectomy during the subsequent spinal contusion surgery (in experimental rat paradigm 2). Overlying muscles were then closed in layers with sterile 4-0 silk sutures, and the skin incision was closed using sterile wound clips. Animals were allowed to recover and monitored daily.

\section{Retrograde anatomical tracing of phrenic motor neurons}

Two weeks before the rats were killed, cholera toxin beta fragment (CT $\beta$ ) conjugated to Alexa555 (Life Technologies) was injected unilaterally into the intrapleural space of the ipsilateral hemidiaphragm muscle (Nicaise et al., 2012a). This procedure allowed for the specific labeling of PhMNs innervating the diaphragm through retrograde transport of CT $\beta$ fluorescent tracer. Following laparotomy under anesthesia, $15 \mu$ l of CT $\beta(0.2 \%$ solution in distilled water) was intrapleurally delivered through the diaphragm (three injections of $5 \mu \mathrm{l}$ each) using a $20 \mu \mathrm{l}$ Hamilton syringe with an attached 33 gauge needle. Abdominal muscles were then sutured with 4-0 sutures, and skin was closed with wound clips.

\section{Tissue processing for histology}

At the time the animals were killed, they were anesthetized, and diaphragm muscle and phrenic nerves were freshly removed before paraformaldehyde perfusion and then further processed for nerve histology and neuromuscular junction (NMJ) labeling. Animals were transcardially perfused with $0.9 \%$ saline, followed by $4 \%$ paraformaldehyde infusion. Spinal cords were harvested, then cryoprotected in $30 \%$ sucrose for $3 \mathrm{~d}$ and embedded in freezing medium. Spinal cord tissue blocks were cut serially in the sagittal or transverse planes at a thickness of $30 \mu \mathrm{m}$. Sections were collected on glass slides and stored at $-20^{\circ} \mathrm{C}$ until analysis. Spinal cord sections were thawed, allowed to dry for $1 \mathrm{~h}$ at room temperature, and stained with $0.5 \%$ cresyl violet acetate according to standard procedure (Nicaise et al., 2012a). For CT $\beta$ and eGFP cell counting, frozen spinal cord sections were airdried, washed, and coverslipped with fluorescent-compatible mounting medium (ProLong Gold, Life Technologies). 


\section{Phrenic nerve histology}

Phrenic nerves were processed as previously described (Kim et al., 2011). Upon removal, phrenic nerves were fixed in $4 \%$ glutaraldehyde solution for $1.5 \mathrm{~h}$, thoroughly washed in Millonig's buffer with $0.5 \%$ (w/v) glucose for $24 \mathrm{~h}$, postfixed in $2 \%(\mathrm{w} / \mathrm{v}) \mathrm{OsO}_{4}$ for $30 \mathrm{~min}$, dehydrated, and embedded in Epoxy resin LX112. Semithin cross sections (1-2 $\mu \mathrm{m}$ thickness) were obtained and stained with $1 \%$ toluidine blue (Sigma-Aldrich) diluted in $2 \%$ sodium borate solution. The total nerve area and the total number of axons and their cross-sectional areas were assessed by two investigators (T.J.H. and C.N.) in a blind manner using ImageJ software, as previously reported (Leroy et al., 2007).

\section{NMJ analysis}

Fresh hemidiaphragm muscle was dissected from each animal for wholemount immunohistochemistry, as described previously (Wright and Son, 2007). Animals that did not receive CT $\beta$ injections were used for this study to avoid overlap of Alexa555-conjugated CT $\beta$ with the rhodamine-conjugated $\alpha$-bungarotoxin used to label the nicotinic acetylcholine receptors. To enable antibody penetration, muscle was stretched, pinned down to Sylgard medium (Fisher Scientific), and extensively cleaned to remove any connective tissue. Motor axons and their terminals were labeled with SMI-312R (Covance) and SV2-s (Developmental Studies Hybridoma Bank), respectively, and both primary antibodies were detected with fluorescin isothiocyanate-conjugated (FITC) anti-mouse IgG secondary antibodies (Jackson ImmunoResearch Laboratories). Postsynaptic acetylcholine receptors were labeled with rhodamine-conjugated $\alpha$-bungarotoxin (Life Technologies). Labeled muscles were analyzed for total numbers of NMJs, fully innervated NMJs, partially denervated NMJs, completely denervated NMJs, NMJs with thin preterminal axons, and multiply-innervated NMJs. The latter two are indicative of motor axon regeneration. Whole-mounted diaphragms were imaged on a FluoView FV1000 confocal microscope (Olympus).

\section{Immunohistochemistry}

Frozen spinal cord sections were air-dried, washed, permeabilized with $0.4 \%$ Triton X-100 in PBS for 5 min at room temperature, and then incubated in blocking solution (PBS containing 10\% normal goat serum and $0.4 \%$ Triton $\mathrm{X}-100$ ) for $1 \mathrm{~h}$ at room temperature. Sections were labeled overnight at $4^{\circ} \mathrm{C}$ with the primary antibodies in blocking solution. Sections were then washed three times with PBS ( 5 min per wash) and incubated with secondary antibodies in blocking solution for $1 \mathrm{~h}$ at room temperature. After washing twice with PBS (10 min per wash), sections were coverslipped. A number of primary antibodies were used. Mouse anti-GFAP (1:200; EMD Millipore) and rabbit anti-GFAP (1:200; Dako North America) were used to label astrocytes (Lepore et al., 2008a). Rabbit anti-Olig2 (1:200; EMD Millipore) was used to label cells of the oligodendrocyte lineage (Lepore et al., 2008a). Mouse anti-NeuN (1:100; EMD Millipore) was used to label neurons (Lepore and Fischer, 2005). Rabbit anti-His (1:50; Cell Signaling Technology) labeled the His-tag fused to GLT1 protein. Rabbit anti-GLT1 (1:800) and mouse anti-GLT1 (1:200) were used to label GLT1 protein (both were provided by Jeffrey Rothstein's laboratory; Lepore et al., 2008b). Rabbit anti-Ki67 (1:200; Thermo Fisher Scientific) labeled proliferating cells (Lepore et al., 2008a). Secondary antibodies included FITC goat-anti-mouse IgG, FITC goat-anti-rabbit IgG, tetramethylrhodamine isothiocyanate (TRITC) goat-anti-mouse IgG, TRITC goat-anti-rabbit IgG, Alexa Fluor 647 goatanti-mouse IgG, Alexa Fluor 647 goat-anti-rabbit IgG. All secondary antibodies were purchased from Jackson ImmunoResearch Laboratories and diluted at 1:200 to recognize the matched primary antibody.

\section{Imaging and quantification}

Images were acquired with either a Zeiss Imager M2 upright microscope or a FluoView FV1000 confocal microscope (Olympus) and then analyzed with ImageJ or MetaMorph software. In SCI paradigms, lesion size was quantified in cresyl violet-stained sections (Nicaise et al., 2012a). Specifically, lesion area was determined in every fifth section by tracing both the total area of the hemispinal cord ipsilateral to the contusion site and the actual lesion area. Lesion was defined as areas including both lost tissue (cystic cavity formation) and surrounding damaged tissue in which the normal anatomical structure of the spinal cord was lost. The lesion epicenter was defined as the section with the largest percentage lesioned tissue (relative to total tissue area in the same section). Lesion volume was determined using the Cavalieri estimator of volume $(V=$ $\left[\Sigma\left(A_{1}+A_{2}+\ldots A_{n}\right) \times D\right]-\left[A_{\max } \times Y\right]$, where $A$ is the area of the lesion, $D$ is the distance between measurements $(150 \mu \mathrm{m})$, and $Y$ is the thickness $(30 \mu \mathrm{m})$ of each section). Ventral horn motor neurons were outlined in these same cresyl violet-stained sections, and the number of motor neuron cell bodies was quantified in a blind manner. Large motor neurons with a clearly identifiable nucleus and a cell soma $>200 \mu \mathrm{m}^{2}$ (Lepore et al., 2011b) or medium-sized neurons (150-200 $\left.\mu \mathrm{m}^{2}\right)$ were counted. $\mathrm{CT} \beta^{+}$PhMN motor neurons were counted in every fifth section across the entire cervical spinal cord and plotted at specific distances relative to the lesion epicenter (Nicaise et al., 2013).

In BAC-GLT1-eGFP mice, eGFP ${ }^{+}$cells were identified in the ventral horn using MetaMorph software (Molecular Devices). Cells were counted and plotted at specific distances relative to lesion epicenter (i.e., 1.5 and $3.0 \mathrm{~mm}$ from the epicenter in both rostral and caudal directions; Lepore et al., 2011a). To quantify GFAP fluorescence signal in the ventral horn, integrated intensities were measured in MetaMorph. GFAP intensity was calculated to be the GFAP-integrated intensity minus the background-integrated intensity of the ventral horn. All GFAP images were acquired using the same exposure settings. In uninjured sham or injured rats injected with AAV-Gfa2-eGFP, numbers of eGFP ${ }^{+}$cells and rostral-caudal spreading of virus transduction were similarly analyzed along the length of the cervical spinal cord.

For in vivo astroglial scar border formation analysis, following immunostaining with mouse anti-GFAP antibody, 3-4 images per animal (at locations surrounding the injury epicenter) were obtained at $5 \times$ magnification. $\mathrm{GFAP}^{+}$astroglial processes immediately adjacent to the lesion, oriented parallel to the border of lesion, and intertwined and overlapped extensively were regarded as the mature border of the astroglial scar (Wanner et al., 2013). Quantification results are presented as the percentage of astroglial scar border length compared with the length of total lesion border.

\section{GLT1 immunoblotting}

Whole-tissue spinal cord samples ( $1.5 \mathrm{~mm}$ length) were homogenized on ice in $0.5 \mathrm{ml}$ of radioimmunoprecipitation assay buffer containing the following (in mM): 50 Tris-HCl, pH 7.6, $150 \mathrm{NaCl}, 2$ EDTA, 0.1\% SDS, $0.01 \%$ NP-40, Protease Inhibitor Cocktail (Roche Diagnostics). Equal amounts of protein (determined by Bradford assay) were resolved by SDS-PAGE on $4-12 \%$ gels and transferred to nitrocellulose membranes. The membranes were blocked in Odyssey blocking buffer (Li-Cor) for $1 \mathrm{~h}$ at room temperature and probed with anti-GLT1 antibody (1:5000) or anti-actin antibody (1:2000; Abcam) overnight followed by incubation with IRDye-conjugated goat-anti-rabbit or goat-anti-mouse IgG (1: 10,000; Li-Cor) as secondary antibody for detection. Acquisition was conducted on a Li-Cor Odyssey infrared imaging system. GLT1 bands were quantified with ImageJ software by integrating band intensity followed by normalization to actin (Lepore et al., 2011c).

\section{Functional glutamate uptake assay}

Glial-restricted precursor (GRP) cells were cultured in differentiation medium consisting of GRP basal medium supplemented with $10 \mathrm{ng} / \mathrm{ml}$ BMP4 and lacking the mitogen bFGF (Davies et al., 2008) for $2 \mathrm{~d}$ and then infected with AAV-Gfa2-eGFP or AAV-Gfa2-GLT1. After $6 \mathrm{~d}$ in culture postinfection, glutamate uptake activity of GRP-derived astrocytes was measured, as previously described (Dowd and Robinson, 1996), with slight modification. Briefly, cells were washed and preincubated with either a sodium-containing or choline-containing uptake buffer [containing (in mM) the following: 5 Tris, 10 HEPES, $140 \mathrm{NaCl}$ or choline chloride, $2.5 \mathrm{KCl}, 1.2 \mathrm{CaCl}_{2}, 1.2 \mathrm{MgCl}_{2}, 1.2 \mathrm{~K}_{2} \mathrm{HPO}_{4}, 10$ glucose] for 20 $\min$ at $37^{\circ} \mathrm{C}$; and in dihydrokainate (DHK) treatment groups, $100 \mu \mathrm{M}$ DHK was added to inhibit GLT1. The uptake buffer was then replaced with fresh uptake buffer containing $20 \mathrm{~nm}{ }^{3} \mathrm{H}$-glutamate $(49 \mathrm{Ci} / \mathrm{mmol}$; PerkinElmer) and $2 \mu \mathrm{M}$ unlabeled glutamate. The cells were incubated for $5 \mathrm{~min}$ at $37^{\circ} \mathrm{C}$. The reaction was terminated by washing cells three times with ice-cold uptake buffer containing 2 mм unlabeled glutamate, 
followed by immediate lysis in ice-cold $0.1 \mathrm{~N} \mathrm{NaOH}$. Cell extracts were then measured with a liquid scintillation counter (Beckman Instruments). The protein content in each well was measured using the Bradford protein assay (Bio-Rad).

\section{In vitro scratch-wound assay}

GLT1-overexpressing GRPs and wild-type GRPs, which both expressed GFP, were induced to differentiate into astrocytes with $10 \mathrm{ng} / \mathrm{ml} \mathrm{BMP-4}$. Astrocytes were cultured until confluent (10-14 d after plating). Scratch wounds were made as described previously (Nishio et al., 2005). Briefly, confluent cultures were scratched with a plastic pipette tip according to a preset grid to induce traumatic injury along the scratch wound. Culture dishes were washed twice with fresh DMEM to remove the debris and incubated with fresh medium for $24 \mathrm{~h}$. The cells were then fixed, and immunostaining was performed with rabbit anti-Ki67 (1:200; Thermo Fisher Scientific) and mouse anti-GFAP (1:200; EMD Millipore) antibodies. Individual images (5-7 per scratch wound) were obtained at $10 \times$ magnification and then analyzed for cell-free area (in $\mathrm{mm}^{2}$ per field), migrating cell numbers at various distances $(D<150 \mu \mathrm{m}$ or $D>150$ $\mu \mathrm{m}$ ), proliferating cell numbers surrounding the wound site (using Ki67 as the proliferation marker), and lengths of migrating-cell processes (visualized with the GFP tag).

\section{Cylinder paw preference test}

All behavioral measurements were conducted on rats starting 2 weeks before injury and thereafter on a weekly basis until they were killed. Rats were weekly video-recorded while rearing freely in a transparent cylinder for $5 \mathrm{~min}$. This test uses spontaneous rearing and exploratory behavior to test forelimb asymmetries under a preference paradigm. Three behaviors were scored during vertical exploration: use of the right ipsilateral forelimb alone, use of the left contralateral forelimb alone, and use of both forelimbs simultaneously. The hit score was expressed as a percentage of usage of each forelimb to total limb usage (Nicaise et al., 2012a).

\section{Grip strength test}

Muscle grip strength was weekly determined for the ipsilateral (right) forelimb using a "grip strength meter" (DFIS-2 Series Digital Force Gauge; Columbus Instruments). Grip strength testing was performed by allowing the rat to grasp a thin bar attached to the force gauge. This was followed by pulling the animal away from the gauge until the forelimb released the bar. The force measurements were averaged from three trials (Nicaise et al., 2012a).

\section{Diaphragm compound muscular action potentials and spontaneous EMG recordings.}

Rats were anesthetized in the same manner described above. Phrenic nerve conduction studies were performed with single stimulation $(0.5 \mathrm{~ms}$ duration; $6 \mathrm{mV}$ amplitude) at the neck via near nerve needle electrodes placed along the phrenic nerve (Lepore et al., 2010). The ground needle electrode was placed in the tail, and the reference electrode was placed subcutaneously in the right abdominal region. Recording was obtained via a surface strip along the costal margin of the diaphragm, and compound muscular action potential (CMAP) amplitude was measured baseline to peak. Recordings were made using an ADI Powerlab 8/30 stimulator and BioAMP amplifier (ADInstruments), followed by computer-assisted data analysis (Scope 3.5.6, ADInstruments). For each animal, 10 tracings were averaged to ensure reproducibility.

Before being killed, animals were anesthetized and received a laparotomy. Bipolar electrodes $3 \mathrm{~mm}$ apart were inserted into several locations in the right hemidiaphragm (Nicaise et al., 2012a). The EMG signal was amplified, filtered through a bandpass filter $(50-3000 \mathrm{~Hz})$, and integrated $(\mathrm{d} V \times \mathrm{d} t)$ using LabChart 7 software (AD Instruments). Parameters, such as respiratory bursts per minute, burst duration, and integrated EMG peak amplitude, were averaged over 2 min sample periods.

\section{Statistics}

Results were expressed as means \pm SEM. A Kolmogorov-Smirnov test was conducted for all variables to assess normality. Unpaired $t$ test or MannWhitney was used to assess statistical significance between two groups. With respect to multiple comparisons involving $\geq 3$ groups, statistical significance was assessed by one-way ANOVA followed by post hoc test (Bonferroni's method). Statistics were computed with Graphpad Prism 5 (GraphPad Software). $p<0.05$ was considered as statistically significant.

\section{Results}

\section{Cervical contusion SCI resulted in both early and chronic downregulation of GLT1 promoter activity and protein expression}

Using BAC-GLT1-eGFP transgenic promoter reporter mice, we spatially and temporally characterized the promoter activity of astrocyte GLT1 following unilateral cervical contusion SCI. In uninjured control mice, GLT1 promoter activity, as detected by $\mathrm{eGFP}^{+}$cells, was abundantly observed in gray matter and to a lesser extent in white matter (Fig. 1A). At 2 DPI, contused spinal cords showed a disruption of spinal cord architecture, including significant loss of $\mathrm{eGFP}^{+}$astrocytes at the lesion epicenter (Fig. $1 B$ ), compared with uninjured animals (Fig. 1A). Highermagnification views (Fig. $1 D, E$ ) of the ventral horn were used to quantify individual $\mathrm{eGFP}^{+}$cells at specific distances from the epicenter, as illustrated in Figure $1 C$. We confirmed that a significant decrease in GLT1 promoter activity occurred as early as 2 DPI in sham versus injured mice $(p<0.001)$ and persisted to 14 and 42 DPI $(p<0.001)$ at the epicenter (Fig. $1 F)$. We next analyzed spinal cord segments rostral (Fig. $1 G, H$ ) and caudal to the epicenter, locations where overt tissue disruption was not observed. In spinal cord ipsilateral to the lesion, the numbers of $\mathrm{eGFP}^{+}$cells $1.5 \mathrm{~mm}$ both rostral and caudal to epicenter were also significantly lower at 2 DPI (Fig. $1 I ; p<0.05$ ). Although significant at only the later time point of 42 DPI (Fig. 1 I; $p<$ $0.05)$, there were trends toward decreased numbers of eGFP ${ }^{+}$ cells at $1.5 \mathrm{~mm}$ both rostrally at $14 \mathrm{DPI}$ and caudally at $42 \mathrm{DPI}$ compared with time-matched uninjured controls. When analyzed at the greater distance of $3.0 \mathrm{~mm}$ rostral and caudal to the epicenter, the numbers of $\mathrm{eGFP}^{+}$cells did not differ statistically between injured and uninjured mice at any time point (Fig. $1 \mathrm{~J}$ ).

To complement these histological studies, we also correlated the downregulation of promoter activity with intraspinal GLT1 protein expression levels using immunoblotting on whole-tissue homogenate subdissected from various spinal cord segments (Fig. 1C). GLT1 protein was highly expressed in uninjured spinal cord, while its expression was significantly reduced following cervical contusion (Fig. $1 K$ ). At the epicenter, quantification of GLT1 immunoblotting showed $\sim 50-80 \%$ downregulation at 2-42 DPI compared with uninjured control (Fig. $1 L$ ). GLT1 protein expression at a spinal cord segment (C6) caudal to the epicenter was not different when comparing injured and uninjured animals (Fig. 1M). Collectively, these results demonstrate that the numbers of GLT1-expressing astrocytes in ventral horn and overall intraspinal GLT1 protein expression were reduced soon after C4-contusion SCI injury and that the decrease persisted chronically for $\geq 6$ weeks.

\section{Lack of GLT1 expression in proliferating, reactive astrocytes following cervical contusion SCI}

We next examined changes in the phenotype of astrocytes using markers of astrocyte reactivity (GFAP) and cell proliferation (Ki67) after cervical contusion SCI. Again using BAC-GLT1eGFP transgenic mice, we correlated these immunohistochemical findings with GLT1 promoter activity. Astrocyte reactivity caused by injury results in robustly increased GFAP expression. In the intact spinal cord, gray matter astrocytes express levels of GFAP protein that are nearly undetectable using immunohistochemistry; therefore, GFAP analysis is an established approach 


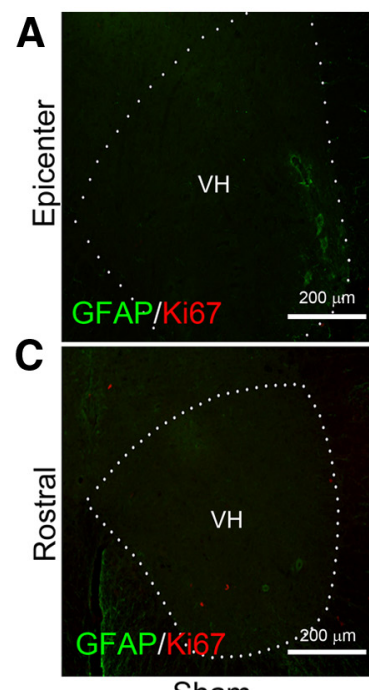

Sham

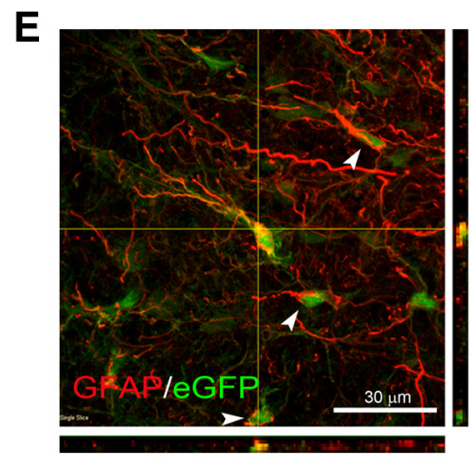

D2
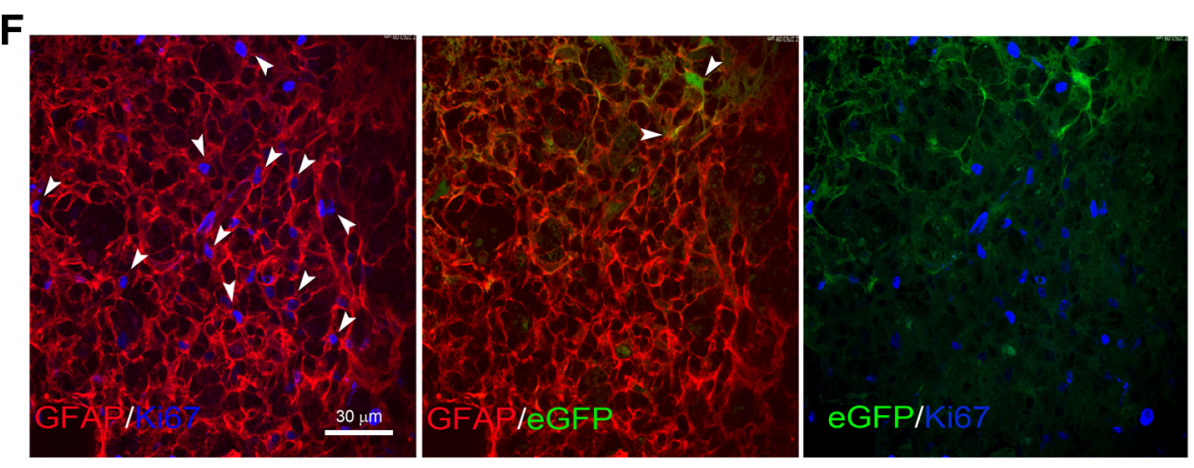

Figure 2. Lack of GLT1 expression in proliferating, reactive astrocytes following cervical-contusion SCl. $\boldsymbol{A}, \boldsymbol{C}$, Immunohistochemistry for GFAP and Ki67 was analyzed in the ventral horn at epicenter $(\boldsymbol{A})$ and rostral (C) locations at day (D) 2, D14, and D42 postinjury. Sham, Laminectomy-only uninjured mice. $\boldsymbol{B}, \boldsymbol{D}$, Quantification of GFAP immunofluorescence intensity and Ki67 ${ }^{+}$cell numbers is shown for epicenter $(\boldsymbol{B})$ and rostral $(\boldsymbol{D})$ ventral horn locations. Results are expressed as means $\pm \mathrm{SEM}$. ${ }^{*} p<0.05,{ }^{* *} p<0.01$ sham versus D2, D14, or D42. $n=6$ mice in sham and D2 groups; $n=7$ in D14 and D42 groups. $\boldsymbol{E}, \boldsymbol{F}$, Confocal images of immunostaining for GFAP/Ki67 in the ventral horn of uninjured BAC-GLT1-eGFP mice $(\boldsymbol{E})$ and injured spinal cord at D14 (F). $\boldsymbol{E}$, Arrowheads, GFAP/eGFP colocalization in the uninjured spinal cord. $\boldsymbol{F}$, Left, Arrowheads, GFAP/Ki67 colocalization in the injured spinal cord, demonstrating extensive astrocyte proliferation. $\boldsymbol{F}$, Center, Arrowheads, Small percentage of GFAP/eGFP colocalization following injury, despite the increased number of GFAP ${ }^{+}$astrocytes. $\boldsymbol{F}$, Right, Proliferating astrocytes did not express GLT1. VH, Ventral horn.

for histologically quantifying astrocyte reactivity at specific anatomical locations. As demonstrated by increased GFAP immunofluorescence intensity, astrocytes displayed dramatic reactivity in the ipsilateral ventral horn starting at 14 and 2 DPI at the lesion epicenter (Fig. $2 A, B$ ) and in intact rostral spinal cord (Fig. 2C,D), respectively, and reactivity persisted to $42 \mathrm{DPI}$. This reactive astrocyte response was associated with marked increases in the numbers of actively proliferating $\mathrm{Ki}^{+}{ }^{+}$cells in the ventral horn at both the lesion epicenter (Fig. $2 A, B$ ) and rostral spinal cord (Fig. $2 C, D$ ) at multiple time points postinjury.

We conducted confocal analysis to characterize changes in the phenotype of individual astrocytes following injury in the context of GLT1 expression and proliferation. In uninjured BAC-GLT1eGFP cervical spinal cord, nearly all GFAP-positive astrocytes expressed GLT1 (Fig. 2E), which coincides with the robust and mostly astrocyte-specific expression of GLT1 in the CNS (Regan et al., 2007). Following cervical-contusion SCI, there was a pronounced reactivity of astrocytes in the ventral horn (both at the lesion epicenter and in intact rostral spinal cord) at all time points characterized by significantly increased expression of GFAP in individual astrocytes, as well as an increase in the total numbers of astrocytes (Fig. 2F). Following injury, there was also a large increase in the number of total proliferating cells in the ventral horn at epicenter and rostral locations, as assessed with Ki67 (Fig.
$2 F)$. A significant percentage of these $\mathrm{Ki}^{+}{ }^{+}$cells were $\mathrm{GFAP}^{+}$ cells (Fig. $2 F$ ), suggesting that astrocyte proliferation at least partially accounted for the increase in number of astrocytes postinjury. Importantly, despite this increase in the number of GFAP ${ }^{+}$ cells, the majority of reactive astrocytes following injury (proliferating astrocytes and/or nondividing astrocytes that have increased GFAP expression) did not express GLT1 (Fig. 2F).

Collectively, these results show that astrocytes of the ventral horn become reactive very early following cervical contusion SCI and remain chronically in a reactive state. In addition, a large portion of the astrocyte population proliferates, particularly with proximity to the site of injury. Despite this robust response that can result in an increase in the number of astrocytes, these reactive cells were compromised in GLT1 expression following cervical SCI, suggesting an inability to properly regulate extracellular glutamate homeostasis.

\section{Intraspinal AAV-mediated gene delivery resulted in} overexpression of normally functioning GLT1 without inducing motor neuron loss or phenotypic impairment

To investigate whether overexpression of exogenous GLT1 in astrocytes protects PhMNs against glutamate excitotoxicity following cervical-contusion (C4) SCI in rats, we intraspinally delivered the GLT1-His fusion gene or eGFP gene using AAV-Gfa2 

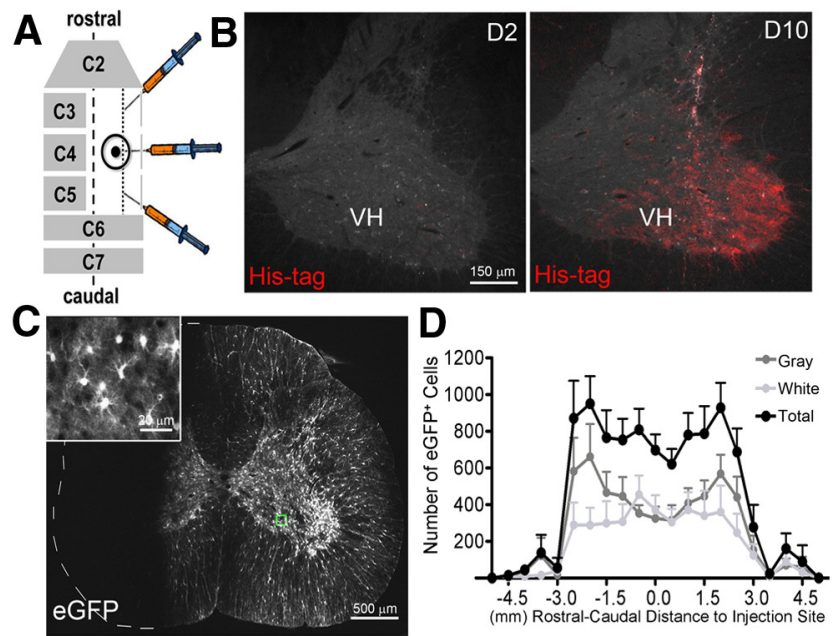

E
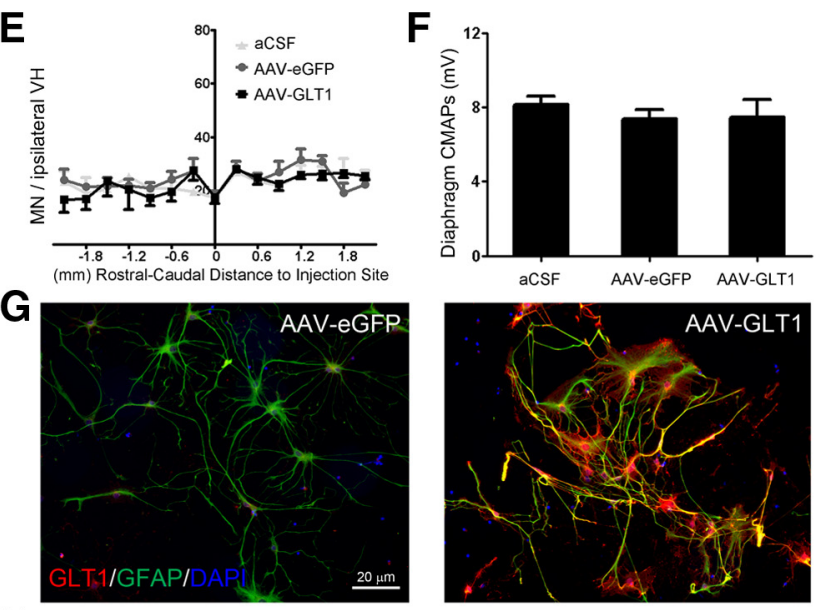

H

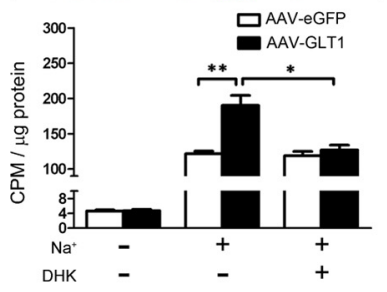

Figure 3. Transduction, functional glutamate uptake, and lack of cytotoxicity following intraspinal AAV-mediated gene delivery. $A, A A V-G f a 2-e G F P$ or AAV-Gfa2-GLT1 was intraspinally injected into ventral horn of rats at $\mathrm{C}$, (4, and C5 levels. $\boldsymbol{B}$, At 10 d postinjection (but not at $2 \mathrm{~d}$ ), His-GLT1 expression was detected in spinal cord with immunostaining for His-tag. C, eGFP signal was detected as the reporter for AAV8 transduction and exogenous gene expression. $C$, Inset, Astrocyte morphology of $\mathrm{Gfa2}-\mathrm{eGFP}^{+}$cells. D, Quantification of eGFP ${ }^{+}$cell numbers at rostral-caudal distances from a single injection site in spinal cord white matter and gray matter. $\boldsymbol{E}, \boldsymbol{F}, \mathrm{AAV}$-Gfa2-eGFP, AAV-Gfa2-GLT1, or artificial CSF (aCSF) as the control was intraspinally injected into uninjured spinal cord, and motor neuron numbers surrounding the injection site $(\boldsymbol{E})$ and phrenic nerve CMAP amplitudes $(\boldsymbol{F})$ were measured at day (D) 10 postinjection to determine whether AAV injection itself or GLT1 overexpression caused histological damage and/or function loss. Results are expressed as means \pm SEM. $n=3$ rats in each group. G, Immunocytochemistry for GFAP and GLT1 on in vitro cultured astrocytes showed lack of GLT1 protein expression following AAV-Gfa2-eGFP infection, while GLT1 was highly expressed in nearly all AAV-Gfa2-GLT1-infected astrocytes. $\boldsymbol{H},{ }^{3} \mathrm{H}$-glutamate uptake assay was performed on in vitro cultured astrocytes following infection with AAV-Gfa2-eGFP or AAV-Gfa2-GLT1. AAV-Gfa2-GLT1 transduction significantly increased levels of sodium-dependent glutamate uptake in astrocytes, which could be blocked by the GLT1 inhibitor, DHK. Results were expressed as means $\pm \mathrm{SEM}$. ${ }^{*} p<$ $0.05,{ }^{* *} p<0.01, n=3$ duplicates for each group.

vectors that drive expression under control of the astrocyte GFAP promoter (Fig. 3A).

We first temporally assessed the time course of exogenous His-GLT1 expression at days 2 and 10 postinjection into the un- injured spinal cord, and found robust expression of His-tagged GLT1 protein in the ventral horn at day 10 postinjection, but little-to-no expression at day 2 (Fig. 3B). We injected AAV-Gfa2eGFP or AAV-Gfa2-GLT1 into the injured spinal cord $10 \mathrm{~d}$ before unilateral $\mathrm{C} 4$ contusion, and we then examined the efficiency and location of transduction by the AAV-Gfa2 vector by detecting eGFP reporter distribution in the cervical spinal cord at day 10 postinjury. Expression of exogenous gene delivered by AAV-Gfa2 vector was highly localized to ventral gray matter, with significant transduction also observed in white matter close to the graywhite matter interface (Fig. $3 B, C$ ). The majority of eGFP-labeled cells possessed an astrocyte-like morphology (Fig. 3C, inset). $\mathrm{eGFP}^{+}$cell counting showed that transduced cells were robustly distributed from $\sim 3 \mathrm{~mm}$ rostral to $3 \mathrm{~mm}$ caudal to a single injection site in both gray and white matter (Fig. 3D).

Although previous reports have shown that exogenous gene expression from AAV is nontoxic (Ponnazhagan et al., 1997; Monahan et al., 2002), we tested potential in vivo cytotoxicity in our experimental paradigm. AAV-Gfa2-GFP or AAV-Gfa2-GLT1 $\left(10^{13}\right.$ genomic particles $\left./ \mathrm{ml}\right)$, or artificial CSF as the control, was injected into ventral horn of the $\mathrm{C} 4$ spinal cord of uninjured rats. At day 10 postinjection, we conducted total motor neuron counts and phrenic nerve-diaphragm CMAP recordings, an in vivo electrophysiological assessment of functional diaphragm innervation by PhMNs (Lepore et al., 2010). There were no significant differences among the three groups in either ventral horn motor neuron numbers across the cervical spinal cord (Fig. $3 E$ ) or peak CMAP amplitudes (Fig. $3 F$ ), demonstrating that AAV injection itself and AAV-based GLT1 overexpression are not toxic in the spinal cord.

To assess the functional glutamate uptake capability of astrocytes transduced with virus, we performed an ${ }^{3} \mathrm{H}$-glutamate uptake assay on cultured astrocytes derived from glial-restricted precursors (a class of lineage-restricted astrocyte progenitor cells; Lepore et al., 2006), which were infected with AAV-Gfa2-eGFP or AAV-Gfa2-GLT1. Nearly all cells in both culture conditions were differentiated GFAP ${ }^{+}$astrocytes (Fig. 3G). GLT1 protein expression was not detected in AAV-Gfa2-eGFP infected cells, which is expected in astrocytes cultured without neurons also present (Yang et al., 2009), while GLT1 was highly expressed in nearly all AAV-Gfa2-GLT1 astrocytes (Fig. 3G). Furthermore, GLT1 overexpression following AAV-Gfa2-GLT1 transduction significantly increased levels of sodium-dependent glutamate uptake in astrocytes $(121.6 \pm 6.4$ vs $190.2 \pm 24.4 \mathrm{cpm} / \mu \mathrm{g}$ protein, $p<0.01)$, which could be blocked by $100 \mu \mathrm{M}$ of the GLT1 inhibitor, DHK $(p<0.05$; Fig. $3 H)$.

Collectively, these results demonstrate that AAV delivery resulted in efficient in vivo transduction and expression of GLT1 protein throughout the cervical spinal cord, did not result in neuronal injury or functional diaphragm impairment, and increased the capacity of astrocytes for functional GLT1-mediated glutamate uptake.

Intraspinal AAV-mediated gene delivery resulted in exogenous GLT1 overexpression specifically in astrocytes We performed double immunostaining for GLT1 and His-tag, which is fused to the N terminus of GLT1, to distinguish exogenous from endogenous GLT1 protein in the injured spinal cord. His-tag colocalized with GLT1 (Fig. 4A, inset), and the His-tag ${ }^{+}$ area showed greater GLT1 immunofluorescence signal than nearby locations containing only endogenous GLT1 expression (Fig. 4A, arrowheads). Immunoblotting of whole-tissue spinal cord homogenate confirmed that total GLT1 protein expression levels in the injured spinal cord were significantly increased in the 

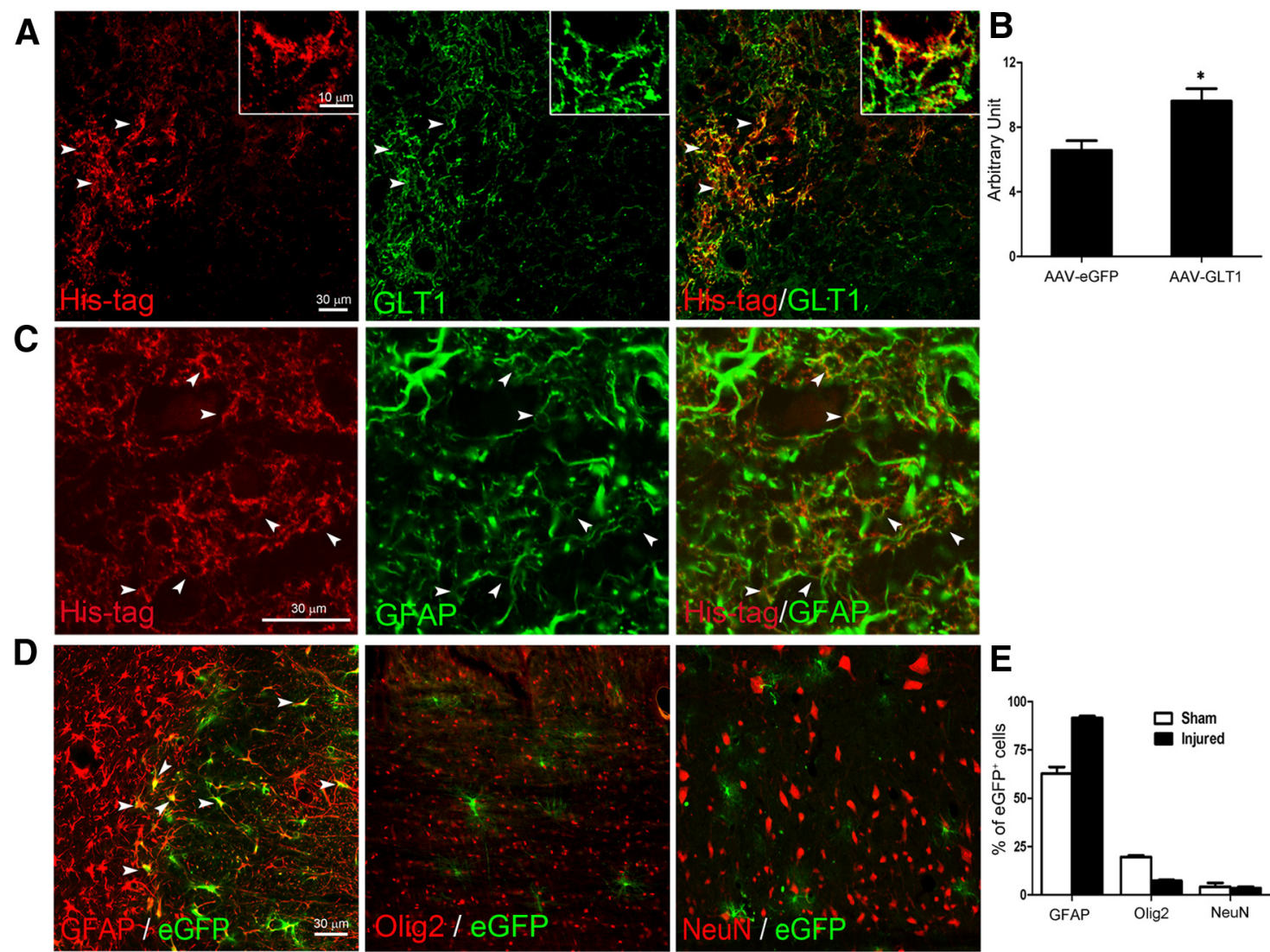

$\mathbf{F}$
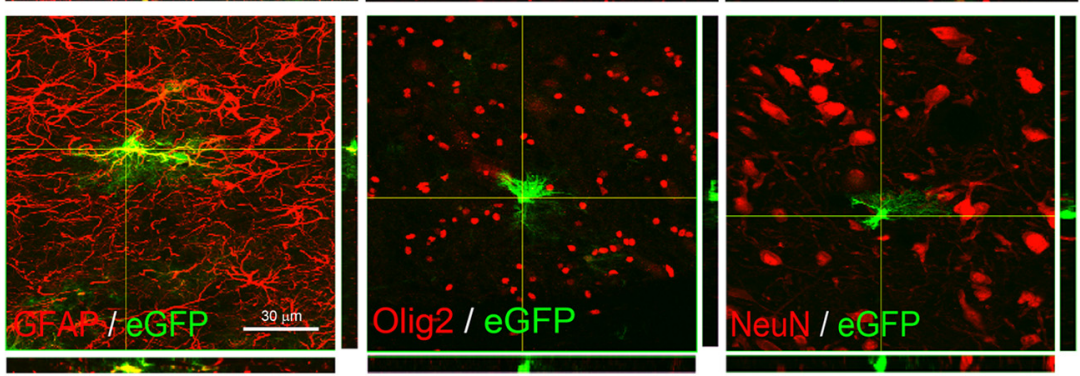

Figure 4. Intraspinal AAV-mediated gene delivery resulted in exogenous GLT1 overexpression specifically in astrocytes. A, Double immunohistochemistry for His-tag and GLT1 showed that the His-tag colocalized with GLT1 protein (arrowheads denote double-labeled cells). Inserts show higher magnification. B, Quantification of GLT1 immunoblotting shows that GLT1 protein expression levels in the spinal cord were increased with AAV-Gfa2-GLT1. C, Double immunohistochemistry for His-tag and GFAP showed that exogenously expressed GLT1 colocalized with GFAP ${ }^{+}$astrocytes (arrowheads denote double-labeled cells). D, Immunohistochemistry for GFAP (astrocytes), Olig2 (oligodendrocyte lineage), and NeuN (neurons) on spinal cord confirmed that AAV transduction was mainly restricted to GFAP ${ }^{+}$astrocytes (arrowheads denote double-labeled cells).E, Percentage of eGFP ${ }^{+}$cells coexpressing GFAP, Olig2, or NeuN in both the uninjured and injured ventral horn. $F$, High-magnification confocal images show that eGFP was highly colocalized with GFAP, but not with Olig2 or NeuN. Results were expressed as means \pm SEM. ${ }^{*} p<0.05$ AAV-Gfa2-GLT1 group versus AAV-Gfa2-eGFP group; $n=5$ rats per group.

AAV-Gfa2-GLT1 group compared with AAV-Gfa2-eGFP control $(p<0.05$; Fig. $4 B)$. Double immunostaining for GFAP and His-tag demonstrated that exogenous His-GLT1 was mainly expressed in $\mathrm{GFAP}^{+}$astrocytes (Fig. 4C, arrowheads). To further quantify the phenotypic identity of transduced cells in the spinal cord, we performed immunostaining for the lineage-specific markers GFAP (astrocytes), Olig2 (cells of the oligodendrocyte lineage), and NeuN (neurons) in both the uninjured (Fig. 4D) and injured (images not shown) spinal cord at day 10 following AAV-Gfa2-eGFP injection. Quantification results show that most $\mathrm{eGFP}^{+}$cells were GFAP ${ }^{+}$astrocytes $(62.8 \pm 3.4 \%$ of all $\mathrm{GFP}^{+}$cells in uninjured tissue, $91.5 \pm 1.0 \%$ in injured tissue), while only a small percentage of eGFP ${ }^{+}$cells were cells of the oligodendrocytes lineage ( $18.5 \pm 0.8 \%$ in uninjured tissue, $6.2 \pm$ $0.5 \%$ in injured tissue) or neurons ( $4.2 \pm 2 \%$ in uninjured tissue, $3.5 \pm 0.7 \%$ in injured tissue; Fig. $4 E$ ). Interestingly, expression in astrocytes was especially pronounced in the injured spinal cord (i.e., 91.5\% of transduced cells and greater eGFP intensity), likely due to the intense activation of the Gfa2 promoter following CNS trauma. High-magnification confocal images further show eGFP colocalization with GFAP, but not with Olig2 or NeuN (Fig. 4F). These results demonstrate that exogenous gene delivered by AAV-Gfa2 vector was specifically expressed in astrocytes in our SCI animal model and that AAV-Gfa2-GLT1 injection significantly increased the intraspinal expression of GLT1 protein in the cervical ventral horn.

\section{Intraspinal GLT1 overexpression in astrocytes increased} PhMN loss following cervical-contusion SCI

Given that astrocyte GLT1 overexpression could be successfully achieved via intraspinal AAV delivery, we sought to determine whether GLT1 overexpression would exert beneficial effects on lesion size and motor neuron loss. We injected AAV-Gfa2-eGFP or AAV-Gfa2-GLT1 into rats $10 \mathrm{~d}$ before $\mathrm{C} 4$ contusion (Figs. $3 \mathrm{~A}$, 
A

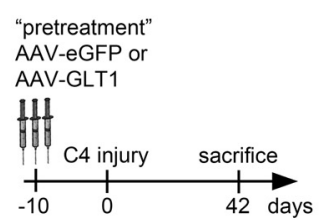

B

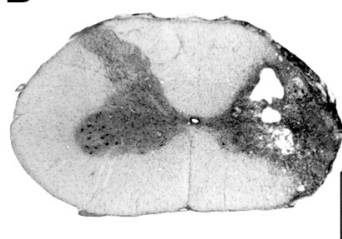

C

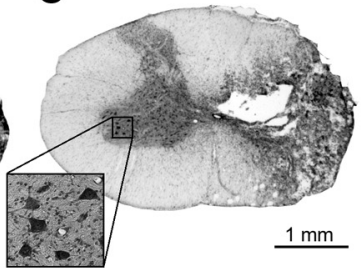

D

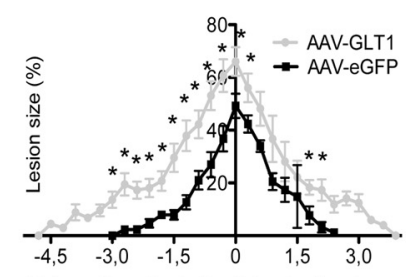

Distance from Contusive Epicenter $(\mathrm{mm})$

G
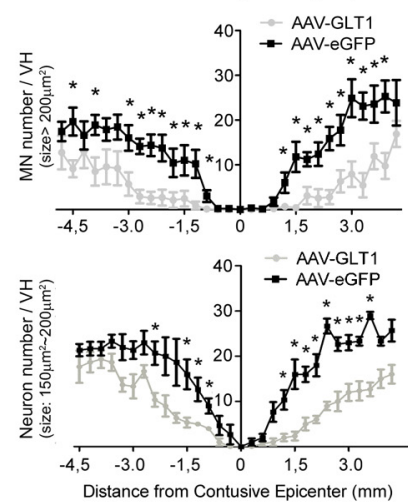

E
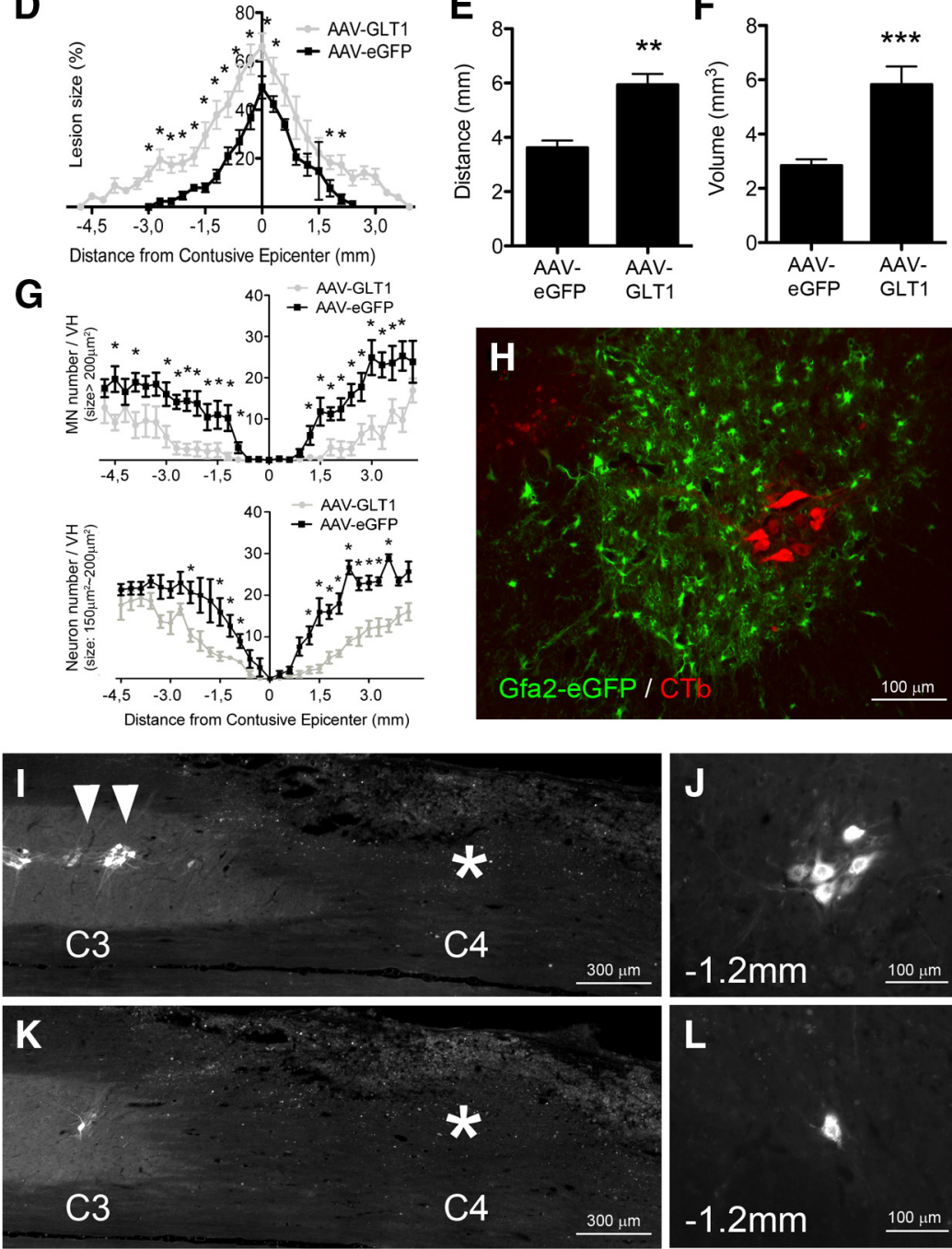

M

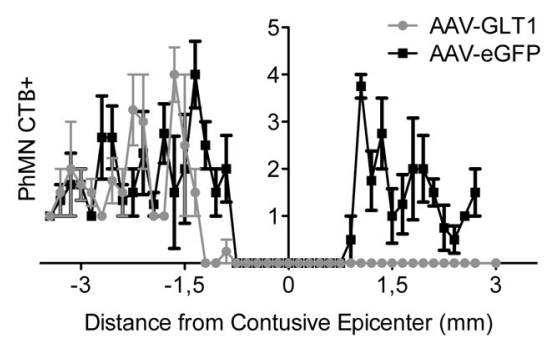

$\mathbf{F}$
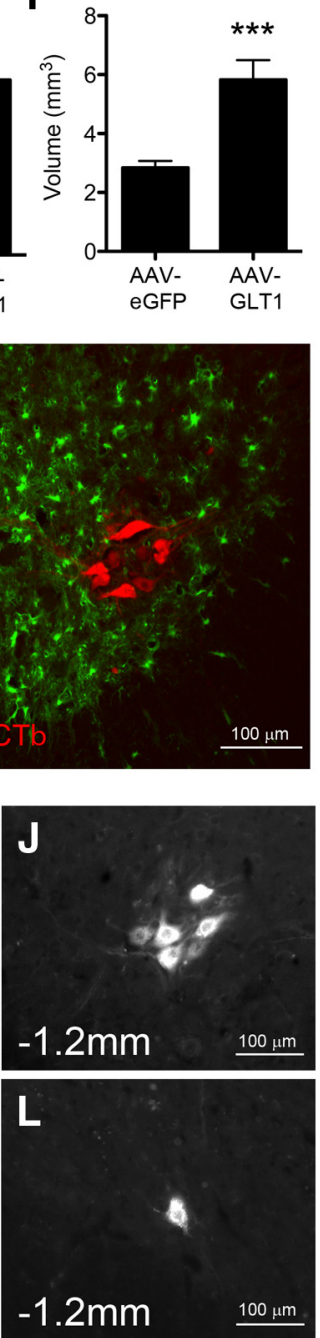

N

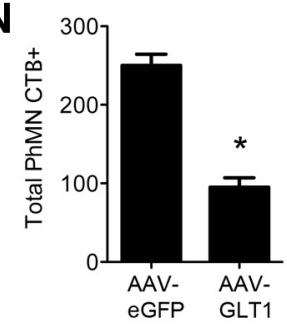

Figure 5. Intraspinal GLT1 overexpression in astrocytes increased PhMN loss following cervical-contusion SCI. A, AAV-Gfa2eGFP or AAV-Gfa2-GLT1 was intraspinally injected into rats $10 \mathrm{~d}$ before (4-contusion SCI. B, C, Representative images of cresyl violet staining illustrate the lesion epicenter in AAV-Gfa2-eGFP $(\boldsymbol{B})$ and AAV-Gfa2-GLT1 $(\boldsymbol{C})$ groups. $\boldsymbol{D}-\boldsymbol{F}$, Lesion size (D), rostralcaudal distance of lesion spread $(\boldsymbol{E})$, and total lesion volume $(\boldsymbol{F})$ were increased in AAV-Gfa2-GLT1 rats compared with AAV-Gfa2eGFP animals. Neuronal populations in the ipsilateral ventral horn were identified ( $\boldsymbol{C}$, inset), quantified, and plotted at multiple distances from epicenter ( $G$, top, large motor neuron numbers; bottom, medium-sized neuron numbers). To specifically visualize PhMNs, CT $\beta$ retrograde tracer was injected into the ipsilateral hemidiaphragm. $\boldsymbol{H}$, Targeting of phrenic nucleus by AAV injections was assessed by visualization of both AAV-Gfa2-eGFP and CT $\beta$. I-L, Representative images show longitudinal $(\boldsymbol{I}, \boldsymbol{K})$ and transverse $(J, L)$ sections of the cervical spinal cord from AAV-Gfa2-eGFP and AAV-Gfa2-GLT1 pretreated rats, revealing ipsilateral labeling of
$5 A)$. These pretreatment injections with AAV were used to provide maximum transduction and GLT1 overexpression in the cervical spinal cord by the time of injury.

When animals were killed at 6 weeks postinjury, overall spinal cord architecture showed greater damage in AAVGfa2-GLT1 rats (Fig. $5 C$ ) than in the control group receiving AAV-Gfa2-eGFP (Fig. 5B). Histological analysis on the ipsilesional side of the spinal cord revealed greater lesion area (in both white and gray matter) at number of rostral-caudal distances surrounding the epicenter $(p<$ 0.01; Fig. 5D), greater rostral-caudal lesion extension (Fig. $5 E$ ), and increased overall lesion volume $(p<0.001$; Fig. $5 F)$ in AAV-Gfa2-GLT1 animals compared with the AAV-Gfa2-eGFP group. We counted neuron numbers with cresyl violet staining (Fig. 5C, inset) at specific distances from the epicenter on the side ipsilateral to the injury. Compared with the control group, GLT1 overexpression resulted in significantly reduced numbers of cervical neurons, including both large motor neurons (Fig. 5G, top graph) and medium-sized nonmotor neurons (Fig. $5 G$, bottom graph), at multiple distances from the lesion epicenter $(p<0.05)$. Nearly all neurons were lost in both groups (Fig. $5 G$ ) very close to the epicenter in our relatively severe contusion model (Nicaise et al., 2012a, 2013), which prevented us from ascertaining the effects of GLT1 overexpression on motor neuron loss at these locations.

To specifically evaluate effects on the phrenic nucleus, we retrogradely labeled PhMNs by injecting CT $\beta$ into the ipsilateral hemidiaphragm. This approach confirmed that AAV gene delivery spatially targeted astrocytes surrounding CT $\beta^{+}$ PhMNs (Fig. 5H). We analyzed CT $\beta$ labeling in both longitudinal (Fig. $5 I, K$ ) and transverse (Fig. 5J,L) spinal cord sections. Increased rostral-caudal extent of

\section{$\leftarrow$}

$\mathrm{CT} \beta^{+}$PhMNs. Injury epicenter is denoted by white asterisk. Loss of CT $\beta$-labeled cells was greater at the rostral C3 (I-L) and caudal $C 5$ (data not shown) boundaries of the lesion in the AAV-Gfa2-GLT1 group $(\boldsymbol{K}, \boldsymbol{L})$ compared with the AAV-Gfa2eGFP group $(\boldsymbol{I}, \boldsymbol{J}) . \boldsymbol{M}$, Quantification of $\mathrm{CT} \beta$-labeled cells shows significant loss of PhMNs at multiple distances from the epicenter. $\boldsymbol{N}$, Increased loss of total CT $\beta$-labeled PhMNs was observed in the AAV-Gfa2-GLT1 group compared with the AAV-Gfa2-eGFP group. Results were expressed as means \pm SEM. ${ }^{*} p<0.05,{ }^{* *} p<0.01,{ }^{* * *} p<0.001$ AAV-Gfa2-GLT1 group versus AAV-Gfa2-eGFP group. $n=11$ rats per group for lesion size analysis and total motor neuron counting; $n=4$ rats per group for $\mathrm{CT} \beta^{+}$PhMN counting. 
A
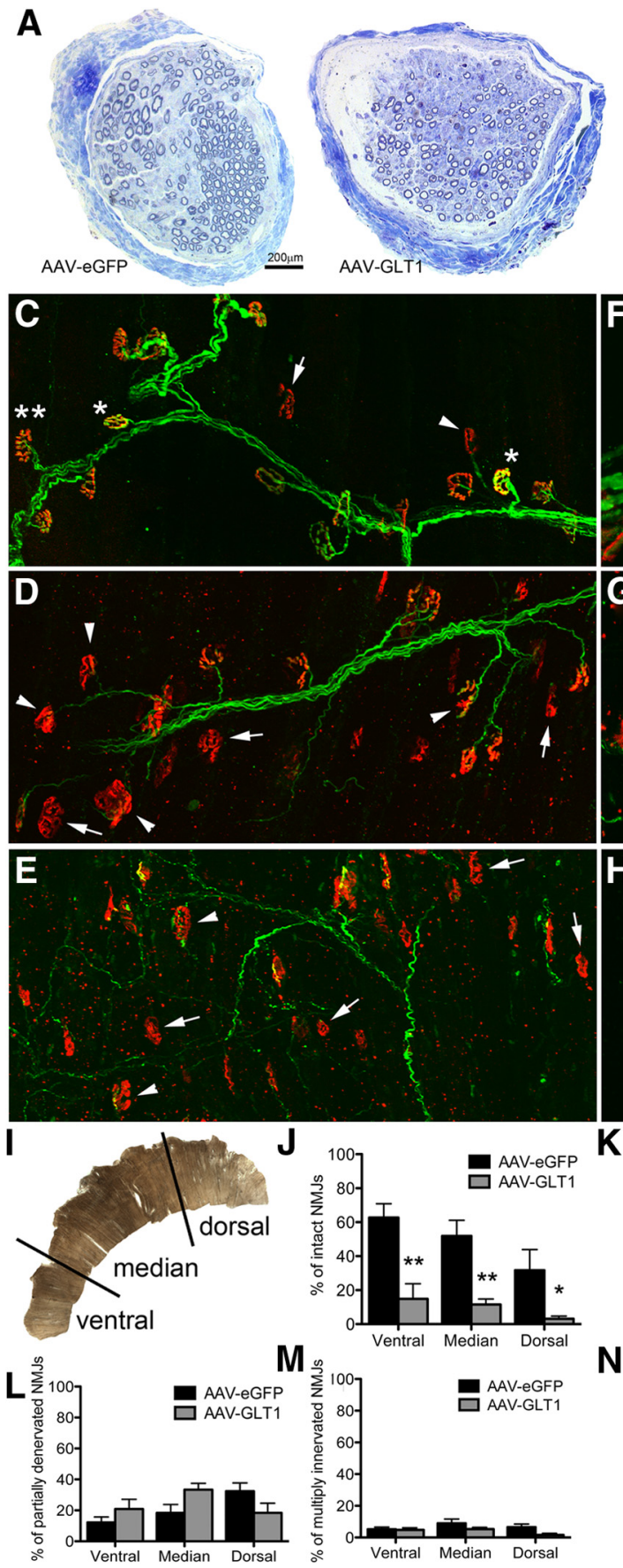

B
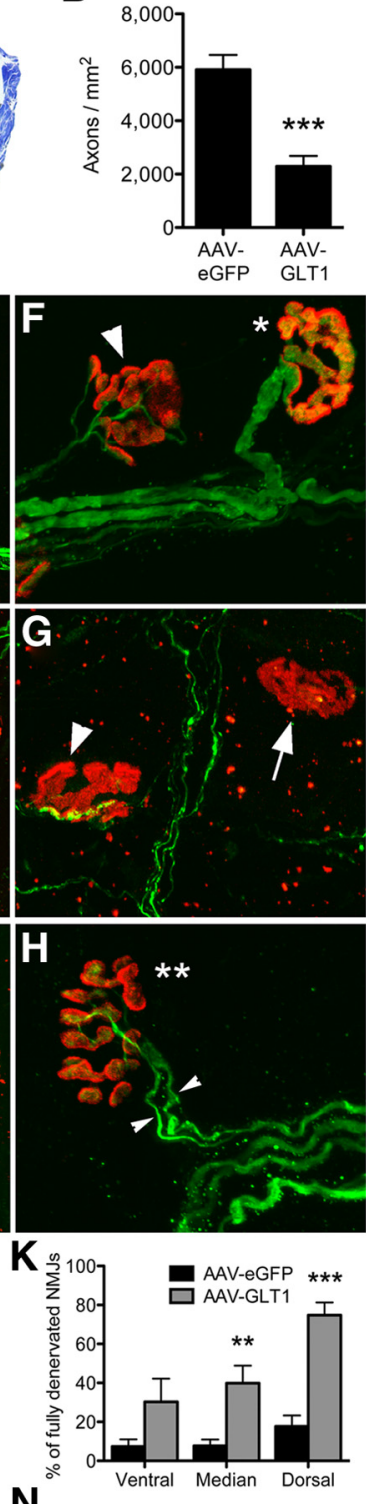

N

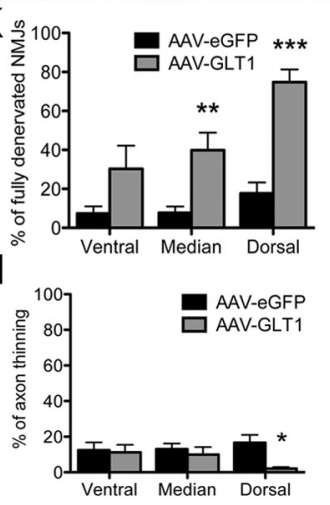

Figure 6. Intraspinal GLT1 overexpression worsened phrenic nerve axonal degeneration and diaphragm denervation. $\boldsymbol{A}$, Phrenic nerve axonal degeneration was observed in both AAV-Gfa2-eGFP and AAV-Gfa2-GLT1 pretreated rats. $\boldsymbol{B}$, Quantification of axonal density revealed a decreased number of intact fibers in the AAV-Gfa2-GLT1 group compared with the AAV-Gfa2-eGFP group. Diaphragm NMJs were assessed via labeling with Alexa-647-conjugated $\alpha$-bungarotoxin (red), SMI-312R (green), and SV2-s (green). $\boldsymbol{C}-\boldsymbol{E}$, While areas of muscle denervation were observed in both AAV-Gfa2-eGFP $(\boldsymbol{C})$ and AAV-Gfa2-GLT1 $(\boldsymbol{D}, \boldsymbol{E})$ groups, reduced numbers of intact NMJs and more widespread areas of denervated NMJs were detected in the AAV-Gfa2-GLT1 group. $\boldsymbol{F}-\boldsymbol{H}$, NMJ morphology analysis was divided into a number of established phenotypic categories: intact ( $\boldsymbol{F}$, asterisk), fully denervated ( $\boldsymbol{G}$, arrow), partially denervated $(\boldsymbol{F}, \boldsymbol{G}$, arrowheads), multiply innervated ( $\boldsymbol{H}$, double asterisk), and preterminal axon thinning. $\boldsymbol{I}$, For analysis, the hemidiaphragm was divided into three anatomical regions (ventral, medial, and dorsal). $\boldsymbol{C}$, Ipsilateral hemidiaphragm from the AAV-Gfa2-eGFP group showed milder NMJ abnormalities. J, In the AAV-Gfa2-GLT1-injected rats, we observed a reduced percentage of intact NMJs compared with AAV-Gfa2-eGFP-injected rats, regardless of the area examined. $\boldsymbol{D}, \boldsymbol{E}$, $\boldsymbol{K}$, Compared with the ventral portion of the muscle in the AAV-Gfa2-GLT1 group (D), medial and dorsal locations in these same AAV-Gfa2-GLT1 animals were particularly affected $(\boldsymbol{E})$, displaying a greater percentage of fully denervated NMJs $(\boldsymbol{K})$. $\boldsymbol{L}, \boldsymbol{M}$, The percentages of NMJs exhibiting partial denervation $(\boldsymbol{L})$ or multiple innervation $(\boldsymbol{M})$ were similar between the two groups. $\boldsymbol{N}$, The percentage of NMJs with signs of preterminal axon thinning was significantly reduced in the AAV-Gfa2-GLT1 group only at the dorsal region. Results were expressed as means \pm SEM. ${ }^{*} p<0.05,{ }^{* *} p<0.01,{ }^{* * *} p<0.001$ AAV-Gfa2-GLT1 group versus AAV-Gfa2-eGFP group. $n=11$ rats per group for phrenic nerve analysis; $n=5$ rats per group for NMJ analysis.

PhMN loss was observed in the AAVGfa2-GLT1 group (Fig. 5K), with the rostral population of PhMNs located at C3-C4 being particularly affected. As previously reported in rats (Mantilla et al., 2009; Nicaise et al., 2012a), PhMNs are concentrated within compact groups of cells forming a linear column throughout the ventromedial region of the $\mathrm{C} 3-\mathrm{C} 5$ ventral horn. Although both AAV groups showed similar PhMN loss at the epicenter, increased survival of CT $\beta^{+}$cells was found in the most rostral (Fig. 5I,J, white arrowheads) and caudal (data not shown) aspects of the cervical region in AAVGfa2-eGFP rats. Only sparse CT $\beta^{+}$cells were observed in the rostral region of AAV-Gfa2-GLT1 rats (Fig. 5L). Quantification at multiple distances from the lesion epicenter further demonstrated greater PhMN loss in the AAV-Gfa2-GLT1 group compared with AAV-Gfa2-eGFP (Fig. 5M). Increased PhMN degeneration was also quantified by estimating the total number of CT $\beta^{+}$PhMNs across the C3-C5 region (ipsilateral to the injury) in the two AAV-injected groups ( $p<0.05$; Fig. $5 N)$.

In summary, these histological results demonstrate that GLT1 overexpression in astrocytes of the ventral horn increased lesion size, total motor neuron loss, and specifically $\mathrm{PhMN}$ loss following cervical contusion SCI.

\section{Intraspinal GLT1 overexpression worsened phrenic nerve axonal degeneration and diaphragm denervation}

We next attempted to correlate central changes observed in the cervical spinal cord with peripheral pathology at the level of both the phrenic nerve and diaphragm NMJ. Anterograde degeneration in the phrenic nerve was more pronounced in the AAV-Gfa2-GLT1 group than in the AAV-Gfa2-eGFP group (Fig. 6A). Quantification of axon density confirmed a significant exacerbation of motor axon loss with AAV-Gfa2-GLT1 (Fig. 6B). To determine whether greater PhMN loss resulted in pathological alterations at the diaphragm NMJ, hemidiaphragm muscle was examined. While areas of muscle denervation were observed in both AAV-Gfa2-eGFP (Fig. 6C) and AAVGfa2-GLT1 (Fig. $6 D, E$ ) groups, reduced numbers of intact NMJs and more widespread areas of denervated NMJs were detected in the AAV-Gfa2-GLT1 group. To specifically characterize the types of pathological changes occurring, NMJ morphology analysis was divided into a number of established phenotypic catego- 
ries: intact (Fig. 6F, asterisk), fully denervated (Fig. 6G, arrow), partially denervated (Fig. 6F, G, arrowheads), multiply innervated (Fig. $6 \mathrm{H}$, double asterisk), and preterminal axon thinning. For analysis, the hemidiaphragm was divided into three anatomical regions (ventral, medial, and dorsal; Fig. 6I), as the rostrocaudal axis of the PhMN pool topographically maps onto the ventrodorsal axis of the diaphragm (Laskowski and Sanes, 1987). Ipsilateral hemidiaphragm from the AAV-Gfa2-eGFP group showed milder NMJ abnormalities (Fig. 6C), to an extent consistent with our previous findings of C4-contusion SCI alone (Nicaise et al., 2012a). In the AAV-Gfa2-GLT1-injected rats, we observed a reduced percentage of intact NMJs compared with AAV-Gfa2eGFP, regardless of the area examined $(p<0.01$ for ventral and medial regions, $p<0.05$ for dorsal region; Fig. $6 J$ ). Compared with the ventral portion of the muscle in the AAV-Gfa2-GLT1 group (Fig. $6 D)$, medial and dorsal locations in these same AAV-Gfa2-GLT1 animals were particularly affected (Fig. 6E), displaying a greater percentage of fully denervated NMJs $(p<0.01$; Fig. $6 K)$. The percentages of NMJs exhibiting partial denervation (Fig. 6L) or multiple innervation (Fig. 6M) were similar between the two groups. The percentage of NMJs with signs of preterminal axon thinning was significantly reduced in the AAV-Gfa2GLT1 group only at the dorsal region $(p<$ 0.05; Fig. $6 N$ ). These muscle histology findings show that PhMN degeneration due to central GLT1 overexpression in the cervical spinal cord resulted in severe pathological effects at the diaphragm NMJ.

\section{Intraspinal GLT1 overexpression worsened both diaphragmatic and forelimb motor dysfunction}

It is important to characterize the in vivo functional effects of AAV-based GLT1 overexpression on both forelimb motor and diaphragmatic function, given that the motor neuron populations innervating these muscles are located in the cervical spinal cord and are profoundly affected by human cervical SCI. We monitored forelimb motor function after cervical contusion weekly for 6 weeks postinjury using grip strength testing and the paw preference/cylinder test. While both AAV groups were chronically impaired up to 42 DPI compared with preinjury baseline, AAV-Gfa2-eGFP animals showed signs of partial grip strength recovery at several time points postinjury compared with AAV-Gfa2-GLT1 rats $(p<0.05$ at 21,28 , and 42 DPI; Fig. 7A). This finding was accompanied by an increased use of ipsilateral forelimb in the cylinder test in the AAV-Gfa2-eGFP group ( $p<0.05$ at 21 and 35 DPI, $p<0.01$ at 42 DPI; Fig. 7B).
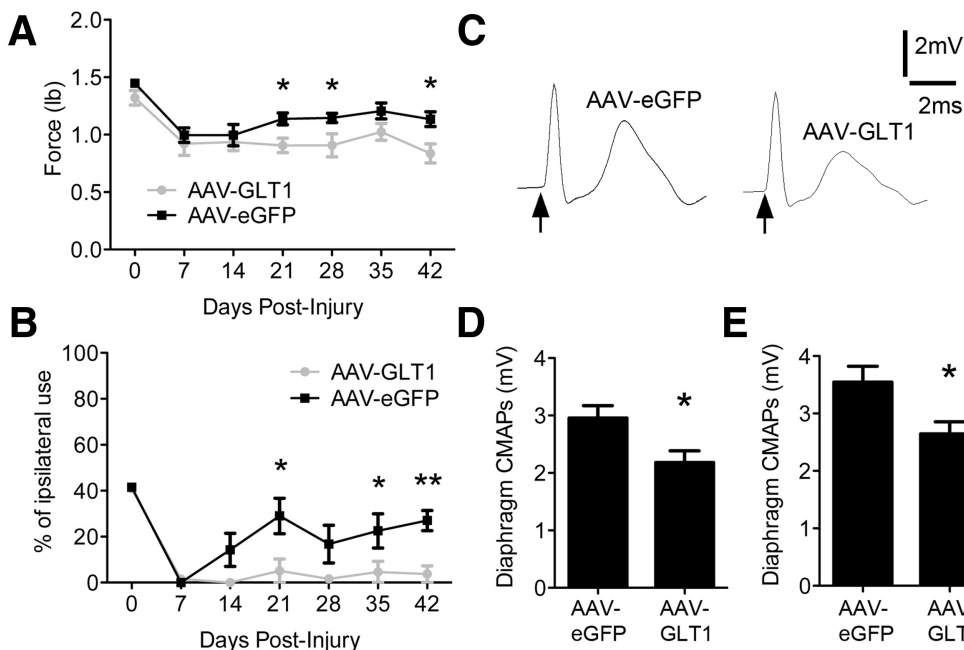

$\mathbf{F}$

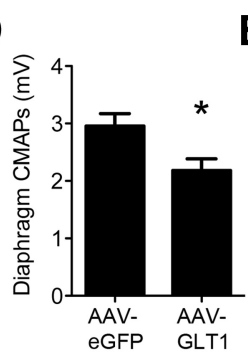

E

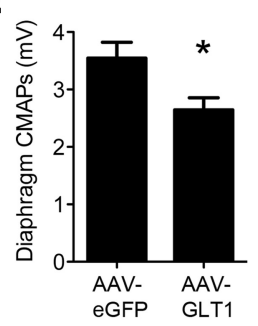

G
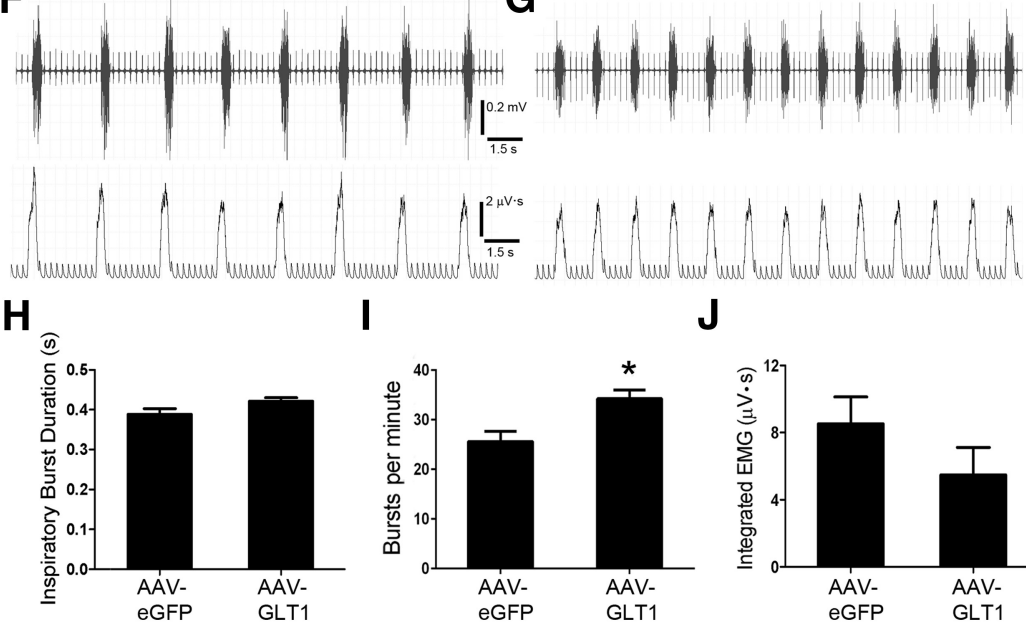

I

J
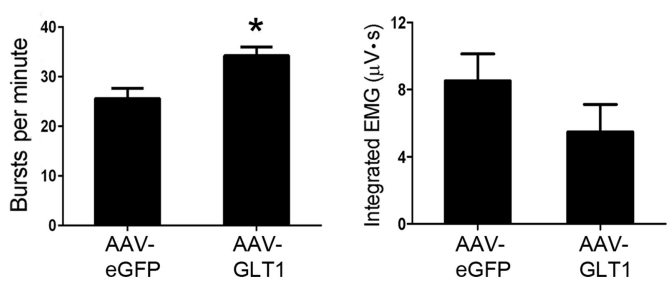

Figure 7. Intraspinal GLT1 overexpression worsened both diaphragmatic and forelimb motor dysfunction. Forelimb motor performance was assessed weekly by grip strength testing of the ipsilateral (right) forelimb and the paw preference test. $\boldsymbol{A}$, Grip strength testing revealed a slight recovery in the AAV-Gfa2-eGFP group, which was not observed in the AAV-Gfa2-GLT1 group. $\boldsymbol{B}$, hemidiaphragm was evaluated using phrenic nerve conduction studies. C, Diaphragm CMAPs obtained following supramaximal (arrows show time of stimulation) were recorded in the ipsilateral hemidiaphragm and showed reduced amplitude for both groups. CMAP amplitudes were $\sim 8 \mathrm{mV}$ in uninjured laminectomy-only rats. $\boldsymbol{D}, \boldsymbol{E}$, Compared with AAV-Gfa2-eGFP, peak CMAP amplitudes were significantly reduced with AAV-Gfa2-GLT1 injection at 2 (D) and 14 (E) DPI. $\boldsymbol{F}$, G, Spontaneous diaphragm grated signals $(\boldsymbol{F}, \mathbf{G}$, bottom). $\boldsymbol{H}-\boldsymbol{J}$, Inspiratory burst duration $(\boldsymbol{H})$, inspiratory bursts per minute $(\boldsymbol{I})$, and integrated EMG amplitude $(\boldsymbol{J})$ in the ipsilateral hemidiaphragm were averaged over a 2 min sample period. Results were expressed as means \pm SEM. ${ }^{*} p<$ $0.05,{ }^{* *} p<0.01$ AAV-Gfa2-GLT1 group versus AAV-Gfa2-eGFP group. $n=11$ rats per group for assessment of forelimb motor function; $n=5-7$ rats per group for CMAP recordings; $n=4$ rats per group for EMG recordings.

In parallel, we electrophysiologically investigated functional innervation of the diaphragm by PhMNs using phrenic nerve conduction studies. Following supramaximal phrenic nerve stimulus, we obtained CMAP recordings from the surface of the ipsilateral hemidiaphragm. In both groups, peak CMAP amplitude was significantly reduced compared with uninjured laminectomy-only animals (Fig. 7C), whose CMAP amplitudes were $\sim 8 \mathrm{mV}$ (data not shown), consistent with our previous findings in this SCI model (Nicaise et al., 2012a). However, CMAP amplitudes in AAV-Gfa2-GLT1 animals were significantly reduced compared with AAV-Gfa2-eGFP at both 2 DPI (Fig. 7D) and 14 DPI (Fig. 7E). Spontaneous diaphragm EMG recordings at $35 \mathrm{DPI}$ from AAV-Gfa2-eGFP (Fig. $7 F$ ) and AAVGfa2-GLT1 (Fig. 7G) groups showed no changes in the duration 
A

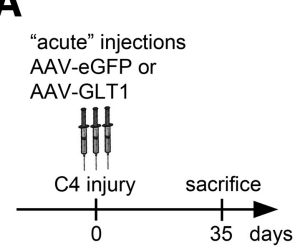

B
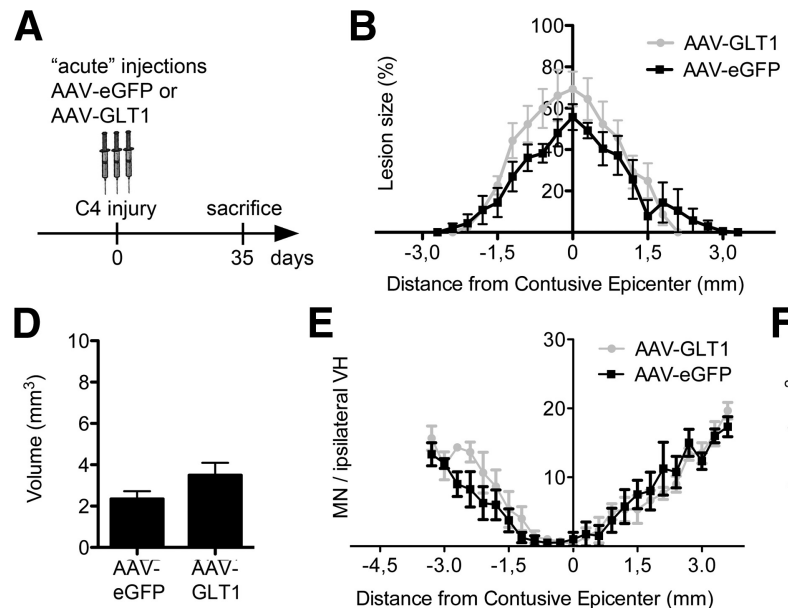

G
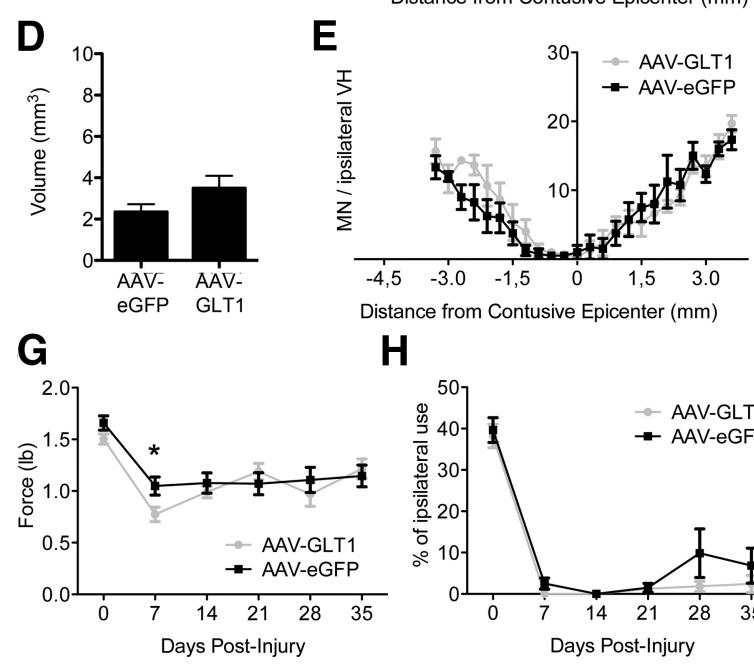

H

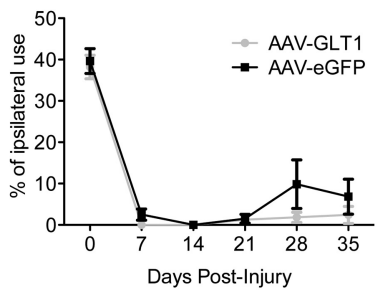

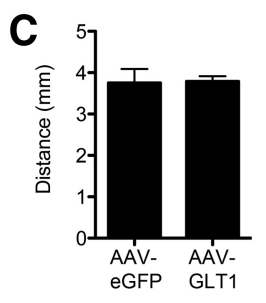

$\mathbf{F}$

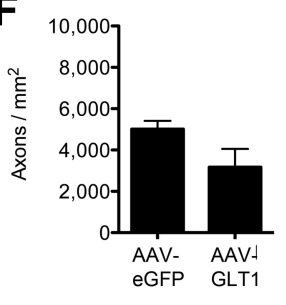

I

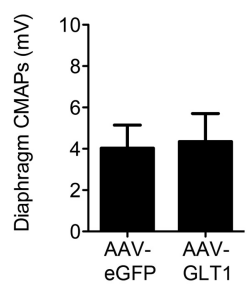

Figure 8. Intraspinal GLT1 gene delivery at the time of cervical-contusion SCI did not affect histological or functional outcomes. AAV-Gfa2-eGFP or AAV-Gfa2-GLT1 vector was intraspinally injected into rats immediately following C 4 contusion. $A$, Animals were killed $35 \mathrm{DPI}$. $\boldsymbol{B}-\boldsymbol{F}$, Lesion size $(\boldsymbol{B})$, rostral - caudal extension of the lesion $(\boldsymbol{C}$ ), total lesion volume $(\boldsymbol{D})$, ipsilateral total motor neuron counts $(\boldsymbol{E})$, and axon density in the ipsilateral phrenic nerve $(\boldsymbol{F})$ did not significantly differ between groups. $\boldsymbol{G}, \boldsymbol{H}$, No differences were noted between groups with grip strength testing $(\boldsymbol{G})$ or the cylinder paw preference test $(\boldsymbol{H}) . \boldsymbol{I}$, Diaphragm CMAP amplitudes did not differ between groups. Results were expressed as means $\pm \mathrm{SEM}$. ${ }^{*} p<0.05$, ${ }^{* *} p<0.01$ AAV-Gfa2-GLT1 group versus AAV-Gfa2-eGFP group. $n=5$ rats per group for lesion size analysis and total motor neuron counting; $n=9$ rats per group for phrenic nerve analysis, assessment of forelimb motor function, and CMAP recordings.

of each discharge (Fig. $7 \mathrm{H}$ ), while the number of inspiratory bursts per minute was significantly increased in the AAV-Gfa2GLT1 group compared with control group (Fig. 7I). The integrated EMG amplitude in the AAV-Gfa2-GLT1 group was slightly reduced compared with the control group; however, this difference was not statistically significant (Fig. $7 J$ ).

These results demonstrate that increased cervical motor neuron loss and diaphragm denervation associated with astrocyte GLT1 overexpression resulted in an actual in vivo worsening of diaphragm and forelimb motor dysfunction in our clinically relevant model of cervical-contusion SCI.

\section{Intraspinal GLT1 gene delivery at the time of cervical- contusion SCI did not affect histological or functional outcome}

We next sought to determine the effects of AAV-Gfa2-GLT1 gene delivery at an "acute" time point by injecting virus immediately following unilateral cervical contusion using the exact same SCI model (Fig. 8A). AAV pretreatment represents a powerful approach for testing proof of principle because it allows for maximal GLT1 overexpression by the time of injury, even if it is not directly relevant to clinical translation. In contrast, the acute injection strategy is a delivery paradigm directly relevant to the potential treatment of cervical SCI patients. Using the same histological analyses employed for the AAV pretreatment studies, we characterized the effects of AAV-Gfa2-eGFP and AAV-Gfa2GLT1 following acute injection. There were no significant differences between virus types in lesion size (Fig. 8B), rostral- caudal extension of the lesion (Fig. $8 C$ ), lesion volume (Fig. 8D), total motor neuron counts (Fig. $8 E$ ), or phrenic nerve axonal loss (Fig. $8 F$ ) at 35 DPI. Given the lack of differences in a number of histological tests, we did not conduct CT $\beta$ or NMJ analyses on these animals. We also conducted functional examination of forelimb motor and diaphragmatic function in the acute injection paradigm. Similar to histological analyses, no differences between groups were noted in ipsilateral forelimb grip strength (Fig. $8 G$ ), ipsilateral forelimb use in the cylinder test (Fig. $8 H$ ), or diaphragm CMAP amplitude at 35 DPI (Fig. 8I).

Last, we also tested delayed injection of $A A V$ vectors at 7 DPI, again using the exact same SCI model as pretreatment and "acute" injection paradigms. With delayed injection of AAV-Gfa2-eGFP and AAV-Gfa2-GLT1, we observed no effects of GLT1 overexpression on lesion measurements, total motor neuron or PhMN loss, diaphragm denervation, or forelimb motor function using histological and functional measures (data not shown).

Unlike the results obtained with pretreatment, our findings with "acute" injection and injection at 7 DPI demonstrate that AAV-GLT1 delivery soon after injury does not modify outcome. These results are likely due to the temporal delay involved in achieving transduction and GLT1 overexpression with intraspinal AAV injection (Fig. 3B). If GLT1 overexpression is to be targeted at early time points postSCI, an alternative strategy to viral vector delivery is likely needed; however, intraspinal injection immediately after injury (or even at very early time points) will likely not be a practically feasible approach for patients. Last, the difference in results between pretreatment and acute/delayed delivery paradigms suggests that the negative effects of GLT1 overexpression are based on events occurring during the initial hours to days post-trauma.

\section{Overexpression of GLT1 reduced astrocyte proliferation and migration, altered astrocyte morphology in vitro, and compromised astroglial scar border formation in vivo} To determine the phenotypic effects of GLT1 overexpression on astrocytes, we performed an in vitro scratch-wound assay and also analyzed astroglial scar formation in vivo following cervical contusion SCI to study the protective scar-forming capacity of astrocytes in response to injury. For the in vitro scratch-wound assay, wound/gap area, astrocyte migration to various distances within the scratch site $(D<150 \mu \mathrm{m}$ or $D>150 \mu \mathrm{m})$, cell proliferation surrounding the wound site, and process length of migrating cells were assessed $24 \mathrm{~h}$ after scratch injury to an astrocyte monolayer was induced (Fig. 9A). Quantification results showed that overexpression of GLT1 using AAV-Gfa2-GLT1 slowed wound healing (Fig. 9B), reduced astrocyte migration (Fig. 9C) and proliferation (Fig. 9D), and shortened the process of migrating astrocytes (Fig. 9E). For the in vivo astroglial scar border formation analysis, immunostaining with anti-GFAP antibody 

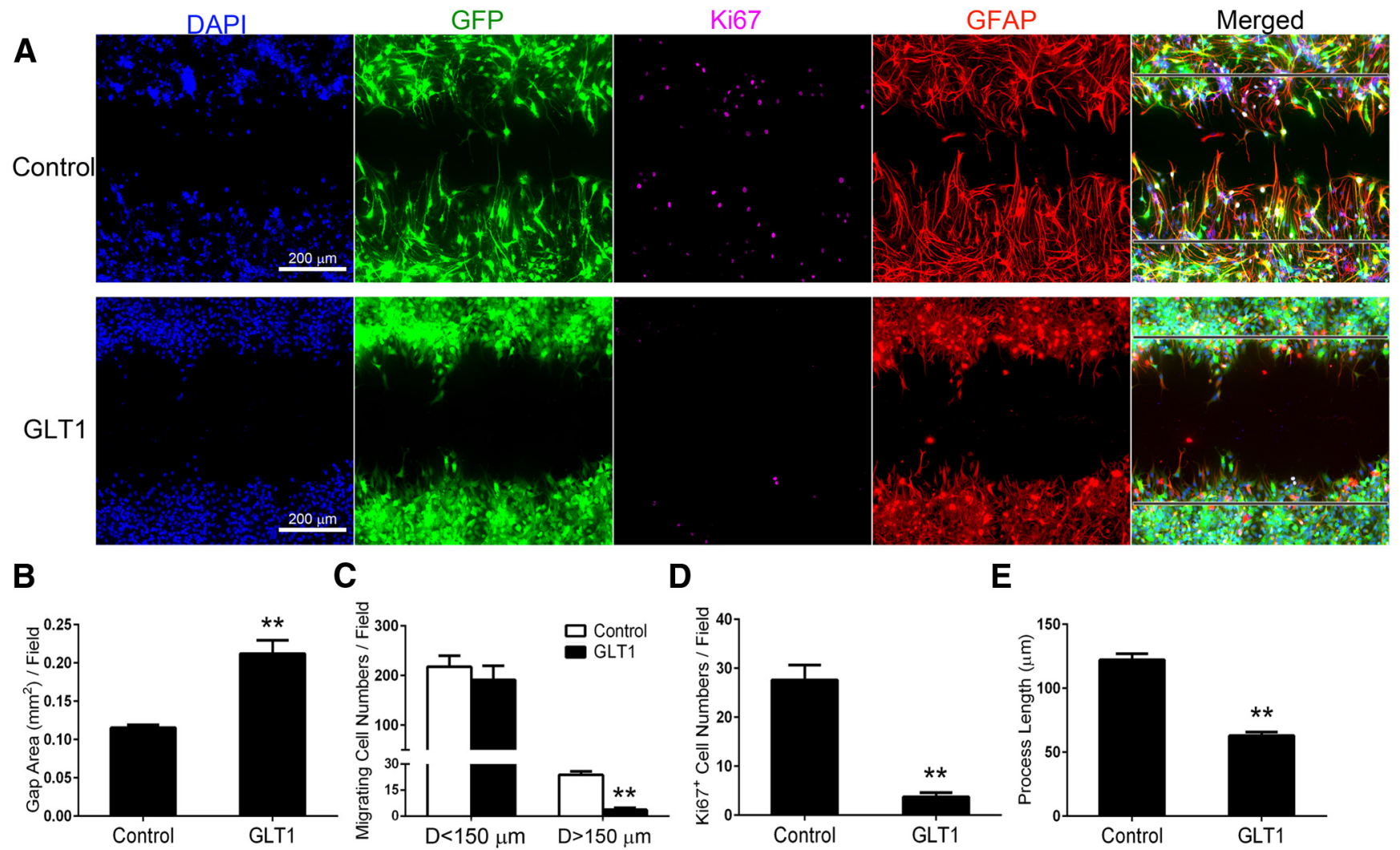

D

E
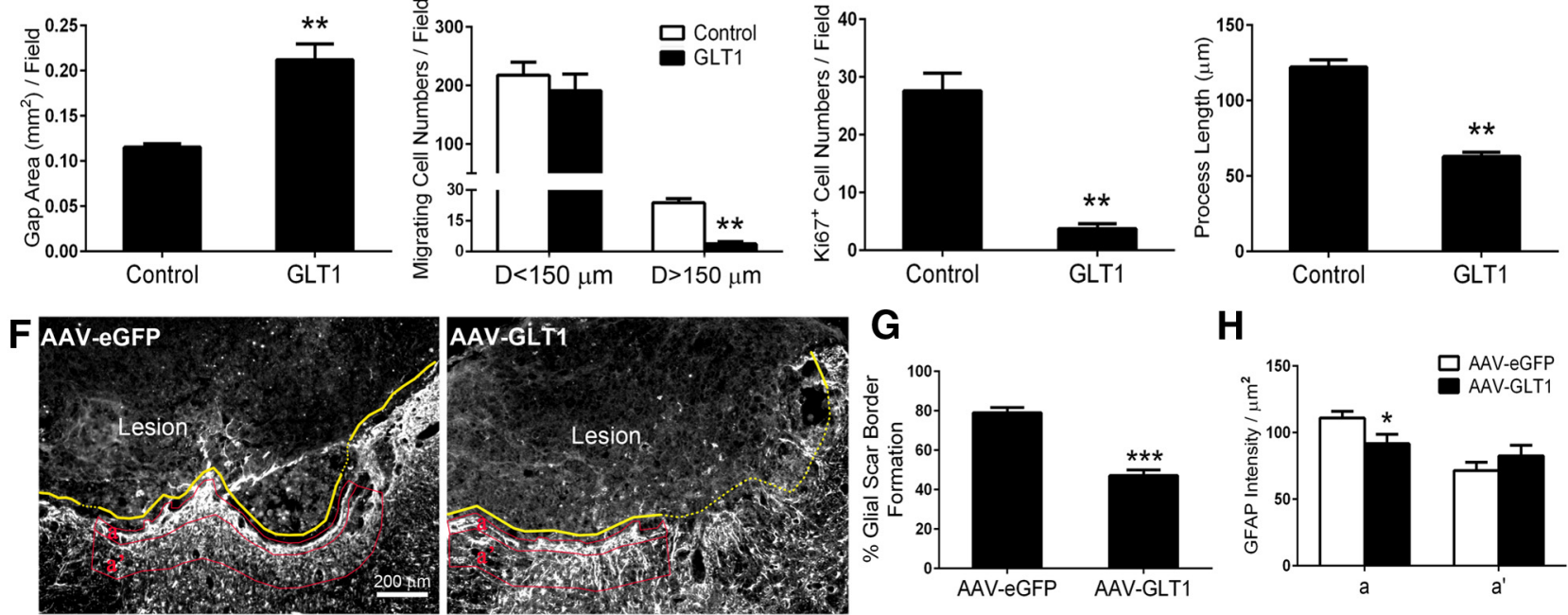

H

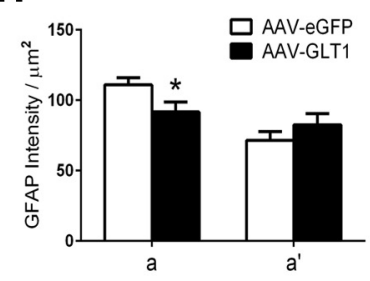

Figure 9. Overexpression of GLT1 reduced astrocyte proliferation and migration, altered astrocyte morphology in vitro, and compromised astroglial scar border formation in vivo. $A$, For the in vitro scratch-wound assay, wound/gap area, astrocyte migration to various distances within the scratch site $(D<150 \mu \mathrm{m}$ or $D>150 \mu \mathrm{m})$, cell proliferation surrounding the wound site, and process length of migrating cells were assessed $24 \mathrm{~h}$ after scratch injury was induced. $\boldsymbol{B}-\boldsymbol{E}$, Quantification results showed that overexpression of GLT1 slowed wound healing $(\boldsymbol{B})$, reduced astrocyte migration $(\boldsymbol{C})$ and proliferation $(\boldsymbol{D})$, and shortened the process of migrating astrocytes $(\boldsymbol{E})$. $\boldsymbol{F}$, For the in vivo astroglial scar border formation analysis, immunostaining with anti-GFAP antibody was performed 3 weeks after injury in the AAV pretreatment delivery paradigm. G, Quantification results show that astroglial scar border formation ( $\boldsymbol{F}$, yellow solid line) in the AAV-Gfa2-GLT1 group was significantly reduced compared with the AAV-Gfa2-eGFP group. $\boldsymbol{H}$, GFAP signal intensity of the scar border ( $\boldsymbol{F}$, red selection, a) in the AAV-Gfa2-GLT1 group was significantly reduced compared with the AAV-Gfa2-eGFP group, while in the area next to the border $\left(\boldsymbol{F}\right.$, red selection, $\left.\mathrm{a}^{\prime}\right)$ GFAP signal intensity was similar between the two groups. Results were expressed as means \pm SEM. ${ }^{*} p<0.05$, ${ }^{* *} p<0.01,{ }^{* *} p<0.001 . n=5-7$ per group for in vitro assay, $n=12-13$ per group for in vivo analysis.

was performed 3 weeks after injury (Fig. $9 F$ ) in the pretreatment virus delivery paradigm. Quantification results show that astroglial scar border formation (Fig. $9 F$, yellow solid line) in the AAVGfa2-GLT1 group was significantly reduced compared with the AAV-Gfa2-eGFP group (Fig. 9G). In addition, GFAP signal intensity of the astrocyte scar border (Fig. $9 F$, red selection: a) in the AAV-Gfa2-GLT1 group was significantly reduced compared with the AAV-Gfa2-eGFP group, while in the area next to the border (Fig. 9F, red selection: a') GFAP signal intensity was similar between the two groups (Fig. 9H). These data show that GLT1 overexpression resulted in a compromised astrogliotic response both in vitro and in vivo, including altered morphology and reduced proliferation, in vitro wound healing, and in vivo scar border formation. These results shed greater light on why GLT1 overexpression in astrocytes worsens outcome in following cervical-contusion SCI model.

\section{Discussion}

In the context of SCI, astrocyte reactivity has traditionally been viewed negatively in association with the astroglial scar and its inhibitory effects on axon regeneration/plasticity. However, astrocytes normally play an integral role in the CNS via a number of important functions (Pekny and Nilsson, 2005). The astrocyte response following SCI should not be approached only as a dichotomy of quiescent versus reactive, but should be viewed as occurring along a spectrum of phenotypes, depending on type, location, timing, and severity of the insult (Sofroniew, 2005). Importantly, it is crucial to study specific astrocyte functions in the diseased nervous system, not just to generalize an astrocyte response. Along these lines, we observed both early and persistent GLT1 expression loss in ventral horn astrocytes following cervical contusion. These findings are in line with previous work from 
our group (Lepore et al., 2011a, 2011c) and from others (VeraPortocarrero et al., 2002; Olsen et al., 2010) demonstrating GLT1 downregulation following thoracic SCI. We also observed pronounced and persistent astrocyte reactivity and even proliferation of some of these cells. Despite this robust response that resulted in increased astrocyte numbers, there were significantly reduced numbers of GLT1-expressing cells as a large portion of the astrocyte population did not express GLT1.

Intraspinal glutamate levels dramatically and rapidly increase following SCI (Panter et al., 1990). Glutamate, when present in excess and/or for too long, is deleterious in vitro and in vivo for neurons and oligodendrocytes (Xu et al., 2008). Riluzole, an "antiglutamatergic" compound whose mechanism of action is not fully understood, improves outcome in a cervical SCI model (Wu et al., 2013). These data suggest that targeting extracellular glutamate dysregulation is a rational strategy for attenuating secondary damage. Even though secondary degeneration is relatively protracted following SCI, temporal dynamics of this process vary across cell types. We previously demonstrated that PhMNs are lost mostly during the first day after cervical contusion (Nicaise et al., 2013), suggesting that early GLT1 downregulation we observed is relevant to $\mathrm{PhMN}$ protection/loss, while persistent decrease in GLT1 is likely more relevant to other SCI outcomes, such as delayed oligodendrocyte injury (Park et al., 2004) and neuronal hyperexcitability (Gwak and Hulsebosch, 2011). Therefore, we chose to test GLT1 overexpression at early time points after injury for $\mathrm{PhMN}$ protection.

To test this hypothesis, we delivered exogenous GLT1 to cervical spinal cord using AAV serotype-8, a nontoxic method (Ponnazhagan et al., 1997; Monahan et al., 2002). As GLT1 is predominantly expressed in astrocytes (Maragakis and Rothstein, 2004), we generated vectors in which the exogenous gene was driven by the GFAP promoter. Considering the delay involved in achieving efficient in vivo virus transduction and subsequent protein expression, we delivered virus using three different temporal paradigms: (1) injection at $10 \mathrm{~d}$ preinjury to assure that GLT1 expression was increased by the time of injury; (2) injection immediately after injury; (3) injection at 7 DPI. We found no differences between the two virus groups in both the second or third injection paradigms, which is likely because the majority of PhMN loss occurs within the first $24 \mathrm{~h}$ after contusion (Nicaise et al., 2013). Surprisingly, we found that pretreatment and consequent GLT1 overexpression at the time of and following injury exacerbated PhMN degeneration and diaphragm dysfunction. While the pretreatment temporal delivery paradigm is not directly relevant for therapy, these exciting findings are still very important for understanding the effects of modulating GLT1 function following SCI using viral or other therapeutic approaches. These findings are in contrast to work showing that partial knockdown in the thoracic crush SCI model using GLT1 heterozygous mice exacerbates lesion spreading and motor deficits (Lepore et al., 2011c). It is possible that reactive astrocytes are not optimal targets for GLT1 overexpression, particularly without modulating overall reactive state of the astrocyte. For example, crush-type SCI also induces astrocyte Kir4.1 potassium channel downregulation (Olsen et al., 2010), which may indirectly affect exogenously expressed GLT1 given the interplay between intracellular/extracellular ion homeostasis and GLT1 function. It therefore may not be enough to just increase GLT1 expression; instead, this approach may need to be conducted in the context of physiologically "healthy" astrocytes.
Along these lines, our observations may be explained by reverse transport. Under such conditions as inversion of the electrochemical gradients of $\mathrm{Na}^{+}$and $\mathrm{K}^{+}$(Grewer et al., 2008), GLT1 can release glutamate into the extracellular space, thereby increasing neuron and oligodendrocyte damage (Matute et al., 2007; Gouix et al., 2009). Hemorrhage, edema, and ischemia can appear within minutes to hours of CNS trauma (Carlson and Gorden, 2002), resulting in GLT1 reversal and consequent glutamate receptor-mediated toxicity (Szatkowski and Attwell, 1994). In our experiments, more GLT1 would be available for such a mechanism. This would be partly consistent with results of ischemic injury. At early stages (i.e., $5 \mathrm{~min}$ ), ischemia-induced glutamate levels in hippocampus of wild-type mice are significantly lower than those in mice lacking GLT1, while after $20 \mathrm{~min}$ of ischemia, glutamate levels in wild-type mice are double those of GLT1 heterozygotes (Mitani and Tanaka, 2003). These results suggest that GLT1 forward transport plays a role in uptake at early stages, while reverse transport may subsequently predominate for some period of time, depending on specifics of the insult (Szatkowski and Attwell, 1994). Since neuron death caused by oxygen-glucose deprivation preconditioning is relieved by downregulating (Wang et al., 2013) or inhibiting (Kosugi and Kawahara, 2006) GLT1, the combination of GLT1 overexpression and selective inhibition of reverse transport may be a successful approach. Unlike the commonly used GLT1 inhibitors DL-threo$\beta$-benzyloxyaspartate (Colleoni et al., 2008) and DHK (Shirasaki et al., 2010), which target both forward and reverse transport, bromocriptine (Shirasaki et al., 2010) and (--3hydroxy-4,5,6,6a-tetrahydro-3aH-pyrrolo[3,4-d]-isoxazole4-carboxylic acid (Colleoni et al., 2008) are thought to mainly inhibit reverse transport.

Astrocytes are more resistant to ischemic injury than neurons (Goldberg and Choi, 1993), possibly because of larger glycogen stores (Cataldo and Broadwell, 1986; Brown and Ransom, 2007) and reduced susceptibility to excitotoxicity (Choi and Rothman, 1990). However, in severe ischemic conditions, loss of the $\mathrm{Na}^{+} / \mathrm{K}^{+}$gradient across the astrocyte plasma membrane can result in astrocyte death in the presence of glutamate (Rossi et al., 2007; Szydlowska et al., 2010). It has been reported that GLT1 reverse transport promotes astrocyte survival by maintaining low intracellular concentrations of $\mathrm{Na}^{+}$and $\mathrm{Ca}^{2+}$ (Kosugi and Kawahara, 2006). In our experiments, GLT1 overexpression may further promote survival of reactive astrocytes. However, chronic astrocyte reactivity may result in a phenotypic switch to a detrimental population. These highly reactive astrocytes could release nitric oxide and reactive oxygen species (Bal-Price and Brown, 2001) that modulate glutamate receptors and consequently lead to damage (Stewart et al., 2002). These cells may also release a variety of cytokines, including $\mathrm{TNF} \alpha$, that are toxic to oligodendrocytes and inhibit neurite outgrowth (D'Souza et al., 1996; Neumann et al., 2002). CCL2, CCL5, and CXCL8 release could also recruit immune cells, leading to inflammatory damage ( $\mathrm{Oh}$ et al., 1999).

After CNS trauma, areas of focal damage are surrounded by an astroglial scar that separates necrotic from spared tissue (Kawano et al., 2012). Transgenic ablation of the proliferating astrocytes that contribute to this process post-SCI leads to increased inflammation, demyelination, lesion volume, and neuronal loss (Faulkner et al., 2004). The glial scar is formed, in part, by proliferating elongated astrocytes. Similarly, when cocultured in vitro with inflammatory cells, astrocytes display bipolar or radial morphologies with elongated processes, and segregate macrophages into discrete clusters (Wanner et al., 2013). In an in vitro 
scratch-wound experiment using astrocyte cultures, we found that GLT1 overexpression reduced astrocyte migration and proliferation, and altered astrocyte morphology such that they displayed shortened processes compared with cells transduced with control virus. Furthermore, in vivo scar formation analysis showed that astroglial scar border formation was significantly compromised in the AAV-GLT1 compared with the control AAV-eGFP group following cervical-contusion SCI. These findings suggest that alteration of the protective scar-forming capacity of astrocytes may be one possible mechanism for the detrimental effects of GLT1 overexpression.

Beneficial effects of GLT1 have been reported in other CNS disease models. For example, GLT1 overexpression reduces ischemic brain injury in a rat stroke model (Harvey et al., 2011). GLT1 knockdown exacerbates hippocampal neuronal damage following traumatic brain injury (Rao et al., 2001). Intraspinal gene transfer of GLT1 attenuates inflammatory and neuropathic pain in rats (Maeda et al., 2008). The discrepancy with our data may be explained, for example, by disease-specific pathological conditions and different spatiotemporal GLT1 expression patterns.

We did not detect motor neuron toxicity or functional impairment with AAV injection into uninjured spinal cord or in the "acute" or "delayed" paradigms postinjury. We found worsening in the pretreatment paradigm only with AAV-GLT1. We observed robust and mostly astrocyte-specific transduction that resulted in significantly increased intraspinal GLT1 expression, with very little ectopic expression in nonastrocyte populations. Last, we found increased functional glutamate uptake with AAVGLT1, demonstrating that transduction resulted in not only protein overexpression but correct membrane localization and transporter function. Together, these results suggest that the observed negative effects were due to increased GLT1 expression in astrocytes and not to the injection procedure, AAV vector, or expression of nonfunctional transporter.

Despite the current results, we still believe that increasing GLT1 is a potentially useful approach. Further studies need to determine the target astrocyte population(s) and correct timing of delivery. Importantly, our findings demonstrate that this AAV-based strategy allows for efficient and long-term gene delivery to spinal cord astrocytes. Furthermore, this anatomically specific approach is crucial for avoiding unwanted side effects. Although AMPA and NMDA antagonists have shown promise for SCI (Wrathall et al., 1994; Agrawal and Fehlings, 1997; Rosenberg et al., 1999; Gaviria et al., 2000), therapeutically targeting glutamate receptor overactivation has diffuse and nonspecific effects in CNS, PNS, and potentially other tissues, as well as only a short temporal duration (Bleakman et al., 2006).

Studies need to model clinically relevant aspects of human SCI. Despite the predominance of cervical contusion in patients, therapies targeting protection of respiratory circuitry have not been extensively tested in appropriate models. The data presented illustrate how our cervical-contusion model and set of histological and functional analyses represents a powerful approach for understanding and treating SCI.

\section{References}

Agrawal SK, Fehlings MG (1997) Role of NMDA and non-NMDA ionotropic glutamate receptors in traumatic spinal cord axonal injury. J Neurosci 17:1055-1063. Medline

Bal-Price A, Brown GC (2001) Inflammatory neurodegeneration mediated by nitric oxide from activated glia-inhibiting neuronal respiration, causing glutamate release and excitotoxicity. J Neurosci 21:6480-6491. Medline
Bleakman D, Alt A, Nisenbaum ES (2006) Glutamate receptors and pain. Semin Cell Dev Biol 17:592-604. CrossRef Medline

Brown AM, Ransom BR (2007) Astrocyte glycogen and brain energy metabolism. Glia 55:1263-1271. CrossRef Medline

Carlson GD, Gorden C (2002) Current developments in spinal cord injury research. Spine J 2:116-128. CrossRef Medline

Cataldo AM, Broadwell RD (1986) Cytochemical identification of cerebral glycogen and glucose-6-phosphatase activity under normal and experimental conditions. II. Choroid plexus and ependymal epithelia, endothelia and pericytes. J Neurocytol 15:511-524. CrossRef Medline

Choi DW, Rothman SM (1990) The role of glutamate neurotoxicity in hypoxic-ischemic neuronal death. Annu Rev Neurosci 13:171-182. CrossRef Medline

Colleoni S, Jensen AA, Landucci E, Fumagalli E, Conti P, Pinto A, De Amici M, Pellegrini-Giampietro DE, De Micheli C, Mennini T, Gobbi M (2008) Neuroprotective effects of the novel glutamate transporter inhibitor (-)-3-hydroxy4,5,6,6a-tetrahydro-3aH-pyrrolo[3,4-d]-isoxazole-4-carboxylic acid, which preferentially inhibits reverse transport (glutamate release) compared with glutamate reuptake. J Pharmacol Exp Ther 326:646-656. CrossRef Medline

Davies JE, Pröschel C, Zhang N, Noble M, Mayer-Pröschel M, Davies SJ (2008) Transplanted astrocytes derived from BMP- or CNTF-treated glial-restricted precursors have opposite effects on recovery and allodynia after spinal cord injury. J Biol 7:24. CrossRef Medline

Dowd LA, Robinson MB (1996) Rapid stimulation of EAAC1-mediated $\mathrm{Na}+$-dependent L-glutamate transport activity in C6 glioma cells by phorbol ester. J Neurochem 67:508-516. Medline

D'Souza SD, Alinauskas KA, Antel JP (1996) Ciliary neurotrophic factor selectively protects human oligodendrocytes from tumor necrosis factormediated injury. J Neurosci Res 43:289-298. CrossRef Medline

Faulkner JR, Herrmann JE, Woo MJ, Tansey KE, Doan NB, Sofroniew MV (2004) Reactive astrocytes protect tissue and preserve function after spinal cord injury. J Neurosci 24:2143-2155. CrossRef Medline

Gaviria M, Privat A, d'Arbigny P, Kamenka J, Haton H, Ohanna F (2000) Neuroprotective effects of a novel NMDA antagonist, gacyclidine, after experimental contusive spinal cord injury in adult rats. Brain Res 874 200-209. CrossRef Medline

Goldberg MP, Choi DW (1993) Combined oxygen and glucose deprivation in cortical cell culture: calcium-dependent and calcium-independent mechanisms of neuronal injury. J Neurosci 13:3510-3524. Medline

Gouix E, Léveillé F, Nicole O, Melon C, Had-Aissouni L, Buisson A (2009) Reverse glial glutamate uptake triggers neuronal cell death through extrasynaptic NMDA receptor activation. Mol Cell Neurosci 40:463-473. CrossRef Medline

Grewer C, Gameiro A, Zhang Z, Tao Z, Braams S, Rauen T (2008) Glutamate forward and reverse transport: from molecular mechanism to transporter-mediated release after ischemia. IUBMB Life 60:609-619. CrossRef Medline

Gwak YS, Hulsebosch CE (2011) Neuronal hyperexcitability: a substrate for central neuropathic pain after spinal cord injury. Curr Pain Headache Rep 15:215-222. CrossRef Medline

Gwak YS, Kang J, Unabia GC, Hulsebosch CE (2012) Spatial and temporal activation of spinal glial cells: role of gliopathy in central neuropathic pain following spinal cord injury in rats. Exp Neurol 234:362-372. CrossRef Medline

Harvey BK, Airavaara M, Hinzman J, Wires EM, Chiocco MJ, Howard DB, Shen H, Gerhardt G, Hoffer BJ, Wang Y (2011) Targeted overexpression of glutamate transporter 1 (GLT-1) reduces ischemic brain injury in a rat model of stroke. PLoS One 6:e22135. CrossRef Medline

Kawano H, Kimura-Kuroda J, Komuta Y, Yoshioka N, Li HP, Kawamura K, Li Y, Raisman G (2012) Role of the lesion scar in the response to damage and repair of the central nervous system. Cell Tissue Res 349:169-180. CrossRef Medline

Kim Y, Park YK, Cho HY, Kim J, Yoon YW (2011) Long-term changes in expressions of spinal glutamate transporters after spinal cord injury. Brain Res 1389:194-199. CrossRef Medline

Kosugi T, Kawahara K (2006) Reversed actrocytic GLT-1 during ischemia is crucial to excitotoxic death of neurons, but contributes to the survival of astrocytes themselves. Neurochem Res 31:933-943. CrossRef Medline

Lane MA, Fuller DD, White TE, Reier PJ (2008) Respiratory neuroplasticity and cervical spinal cord injury: translational perspectives. Trends Neurosci 31:538-547. CrossRef Medline 
Laskowski MB, Sanes JR (1987) Topographic mapping of motor pools onto skeletal muscles. J Neurosci 7:252-260. Medline

Lepore AC (2011) Intraspinal cell transplantation for targeting cervical ventral horn in amyotrophic lateral sclerosis and traumatic spinal cord injury. J Vis Exp (55):pii:3069. CrossRef Medline

Lepore AC, Fischer I (2005) Lineage-restricted neural precursors survive, migrate, and differentiate following transplantation into the injured adult spinal cord. Exp Neurol 194:230-242. CrossRef Medline

Lepore AC, Maragakis NJ (2011) Stem cell transplantation for spinal cord neurodegeneration. Methods Mol Biol 793:479-493. CrossRef Medline

Lepore AC, Walczak P, Rao MS, Fischer I, Bulte JW (2006) MR imaging of lineage-restricted neural precursors following transplantation into the adult spinal cord. Exp Neurol 201:49-59. CrossRef Medline

Lepore AC, Dejea C, Carmen J, Rauck B, Kerr DA, Sofroniew MV, Maragakis NJ (2008a) Selective ablation of proliferating astrocytes does not affect disease outcome in either acute or chronic models of motor neuron degeneration. Exp Neurol 211:423-432. CrossRef Medline

Lepore AC, Rauck B, Dejea C, Pardo AC, Rao MS, Rothstein JD, Maragakis NJ (2008b) Focal transplantation-based astrocyte replacement is neuroprotective in a model of motor neuron disease. Nat Neurosci 11:1294-1301. CrossRef Medline

Lepore AC, Tolmie C, O’Donnell J, Wright MC, Dejea C, Rauck B, Hoke A, Ignagni AR, Onders RP, Maragakis NJ (2010) Peripheral hyperstimulation alters site of disease onset and course in SOD1 rats. Neurobiol Dis 39:252-264. CrossRef Medline

Lepore AC, O’Donnell J, Bonner JF, Paul C, Miller ME, Rauck B, Kushner RA, Rothstein JD, Fischer I, Maragakis NJ (2011a) Spatial and temporal changes in promoter activity of the astrocyte glutamate transporter GLT1 following traumatic spinal cord injury. J Neurosci Res 89:1001-1017. CrossRef Medline

Lepore AC, O’Donnell J, Kim AS, Williams T, Tuteja A, Rao MS, Kelley LL, Campanelli JT, Maragakis NJ (2011b) Human glial-restricted progenitor transplantation into cervical spinal cord of the SOD1 mouse model of ALS. PLoS One 6:e25968. CrossRef Medline

Lepore AC, O’Donnell J, Kim AS, Yang EJ, Tuteja A, Haidet-Phillips A, O'Banion CP, Maragakis NJ (2011c) Reduction in expression of the astrocyte glutamate transporter, GLT1, worsens functional and histological outcomes following traumatic spinal cord injury. Glia 59:1996-2005. CrossRef Medline

Leroy K, Bretteville A, Schindowski K, Gilissen E, Authelet M, De Decker R, Yilmaz Z, Buée L, Brion JP (2007) Early axonopathy preceding neurofibrillary tangles in mutant tau transgenic mice. Am J Pathol 171:976-992. CrossRef Medline

Liu D, Thangnipon W, McAdoo DJ (1991) Excitatory amino acids rise to toxic levels upon impact injury to the rat spinal cord. Brain Res 547:344348. CrossRef Medline

Maeda S, Kawamoto A, Yatani Y, Shirakawa H, Nakagawa T, Kaneko S (2008) Gene transfer of GLT-1, a glial glutamate transporter, into the spinal cord by recombinant adenovirus attenuates inflammatory and neuropathic pain in rats. Mol Pain 4:65. CrossRef Medline

Mantilla CB, Zhan WZ, Sieck GC (2009) Retrograde labeling of phrenic motoneurons by intrapleural injection. J Neurosci Methods 182:244249. CrossRef Medline

Maragakis NJ, Rothstein JD (2004) Glutamate transporters: animal models to neurologic disease. Neurobiol Dis 15:461-473. CrossRef Medline

Matute C, Alberdi E, Domercq M, Sánchez-Gómez MV, Pérez-Samartín A, Rodríguez-Antigüedad A, Pérez-Cerdá F (2007) Excitotoxic damage to white matter. J Anat 210:693-702. CrossRef Medline

McAdoo DJ, Xu GY, Robak G, Hughes MG (1999) Changes in amino acid concentrations over time and space around an impact injury and their diffusion through the rat spinal cord. Exp Neurol 159:538-544. CrossRef Medline

Min KJ, Jeong HK, Kim B, Hwang DH, Shin HY, Nguyen AT, Kim JH, Jou I, Kim BG, Joe EH (2012) Spatial and temporal correlation in progressive degeneration of neurons and astrocytes in contusion-induced spinal cord injury. J Neuroinflammation 9:100. CrossRef Medline

Mitani A, Tanaka K (2003) Functional changes of glial glutamate transporter GLT-1 during ischemia: an in vivo study in the hippocampal CA1 of normal mice and mutant mice lacking GLT-1. J Neurosci 23:71767182. Medline

Monahan PE, Jooss K, Sands MS (2002) Safety of adeno-associated virus gene therapy vectors: a current evaluation. Expert Opin Drug Saf 1:79-91. CrossRef Medline

Neumann H, Schweigreiter R, Yamashita T, Rosenkranz K, Wekerle H, Barde YA (2002) Tumor necrosis factor inhibits neurite outgrowth and branching of hippocampal neurons by a rho-dependent mechanism. J Neurosci 22:854-862. Medline

Nicaise C, Hala TJ, Frank DM, Parker JL, Authelet M, Leroy K, Brion JP, Wright MC, Lepore AC (2012a) Phrenic motor neuron degeneration compromises phrenic axonal circuitry and diaphragm activity in a unilateral cervical contusion model of spinal cord injury. Exp Neurol 235:539552. CrossRef Medline

Nicaise C, Putatunda R, Hala TJ, Regan KA, Frank DM, Brion JP, Leroy K, Pochet R, Wright MC, Lepore AC (2012b) Degeneration of phrenic motor neurons induces long-term diaphragm deficits following mid-cervical spinal contusion in mice. J Neurotrauma 29:2748-2760. CrossRef Medline

Nicaise C, Frank DM, Hala TJ, Authelet M, Pochet R, Adriaens D, Brion JP, Wright MC, Lepore AC (2013) Early phrenic motor neuron loss and transient respiratory abnormalities after unilateral cervical spinal cord contusion. J Neurotrauma 30:1092-1099. CrossRef Medline

Nishio T, Kawaguchi S, Yamamoto M, Iseda T, Kawasaki T, Hase T (2005) Tenascin-C regulates proliferation and migration of cultured astrocytes in a scratch wound assay. Neuroscience 132:87-102. CrossRef Medline

Oh JW, Schwiebert LM, Benveniste EN (1999) Cytokine regulation of CC and CXC chemokine expression by human astrocytes. J Neurovirol 5:8294. CrossRef Medline

Olsen ML, Campbell SC, McFerrin MB, Floyd CL, Sontheimer H (2010) Spinal cord injury causes a wide-spread, persistent loss of Kir4.1 and glutamate transporter 1: benefit of 17 beta-oestradiol treatment. Brain 133:1013-1025. CrossRef Medline

Oyinbo CA (2011) Secondary injury mechanisms in traumatic spinal cord injury: a nugget of this multiply cascade. Acta Neurobiol Exp (Wars) 71:281-299. Medline

Panter SS, Yum SW, Faden AI (1990) Alteration in extracellular amino acids after traumatic spinal cord injury. Ann Neurol 27:96-99. CrossRef Medline

Park E, Velumian AA, Fehlings MG (2004) The role of excitotoxicity in secondary mechanisms of spinal cord injury: a review with an emphasis on the implications for white matter degeneration. J Neurotrauma 21: 754-774. CrossRef Medline

Pekny M, Nilsson M (2005) Astrocyte activation and reactive gliosis. Glia 50:427-434. CrossRef Medline

Ponnazhagan S, Mukherjee P, Yoder MC, Wang XS, Zhou SZ, Kaplan J, Wadsworth S, Srivastava A (1997) Adeno-associated virus 2-mediated gene transfer in vivo: organ-tropism and expression of transduced sequences in mice. Gene 190:203-210. CrossRef Medline

Rao VL, Dogan A, Bowen KK, Todd KG, Dempsey RJ (2001) Antisense knockdown of the glial glutamate transporter GLT-1 exacerbates hippocampal neuronal damage following traumatic injury to rat brain. Eur J Neurosci 13:119-128. CrossRef Medline

Regan MR, Huang YH, Kim YS, Dykes-Hoberg MI, Jin L, Watkins AM, Bergles DE, Rothstein JD (2007) Variations in promoter activity reveal a differential expression and physiology of glutamate transporters by glia in the developing and mature CNS. J Neurosci 27:6607-6619. CrossRef Medline

Rosenberg LJ, Teng YD, Wrathall JR (1999) 2,3-Dihydroxy-6-nitro-7sulfamoyl-benzo(f)quinoxaline reduces glial loss and acute white matter pathology after experimental spinal cord contusion. J Neurosci 19:464475. Medline

Rossi DJ, Brady JD, Mohr C (2007) Astrocyte metabolism and signaling during brain ischemia. Nat Neurosci 10:1377-1386. CrossRef Medline

Shirasaki Y, Sugimura M, Sato T (2010) Bromocriptine, an ergot alkaloid, inhibits excitatory amino acid release mediated by glutamate transporter reversal. Eur J Pharmacol 643:48-57. CrossRef Medline

Sofroniew MV (2005) Reactive astrocytes in neural repair and protection. Neuroscientist 11:400-407. CrossRef Medline

Stewart VC, Heslegrave AJ, Brown GC, Clark JB, Heales SJ (2002) Nitric oxide-dependent damage to neuronal mitochondria involves the NMDA receptor. Eur J Neurosci 15:458-464. CrossRef Medline

Strakowski JA, Pease WS, Johnson EW (2007) Phrenic nerve stimulation in the evaluation of ventilator-dependent individuals with C4- and C5-level spinal cord injury. Am J Phys Med Rehabil 86:153-157. CrossRef Medline 
Szatkowski M, Attwell D (1994) Triggering and execution of neuronal death in brain ischaemia: two phases of glutamate release by different mechanisms. Trends Neurosci 17:359-365. CrossRef Medline

Szydlowska K, Gozdz A, Dabrowski M, Zawadzka M, Kaminska B (2010) Prolonged activation of ERK triggers glutamate-induced apoptosis of astrocytes: neuroprotective effect of FK506. J Neurochem 113:904-918. CrossRef Medline

Tanaka K, Watase K, Manabe T, Yamada K, Watanabe M, Takahashi K, Iwama H, Nishikawa T, Ichihara N, Kikuchi T, Okuyama S, Kawashima N, Hori S, Takimoto M, Wada K (1997) Epilepsy and exacerbation of brain injury in mice lacking the glutamate transporter GLT-1. Science 276:1699-1702. CrossRef Medline

Vera-Portocarrero LP, Mills CD, Ye Z, Fullwood SD, McAdoo DJ, Hulsebosch CE, Westlund KN (2002) Rapid changes in expression of glutamate transporters after spinal cord injury. Brain Res 927:104-110. CrossRef Medline

Wang D, Zhao Y, Zhang Y, Zhang T, Shang X, Wang J, Liu Y, Kong Q, Sun B, Mu L, Liu X, Wang G, Li H (2013) Hypothermia protects against oxygen-glucose deprivation-induced neuronal injury by down-regulating the reverse transport of glutamate by astrocytes as mediated by neurons. Neuroscience 237:130-138. CrossRef Medline

Wanner IB, Anderson MA, Song B, Levine J, Fernandez A, Gray-Thompson Z, Ao Y, Sofroniew MV (2013) Glial scar borders are formed by newly proliferated, elongated astrocytes that interact to corral inflammatory and fibrotic cells via STAT3-dependent mechanisms after spinal cord injury. J Neurosci 33:12870-12886. CrossRef Medline

Weller ML, Stone IM, Goss A, Rau T, Rova C, Poulsen DJ (2008) Selective overexpression of excitatory amino acid transporter 2 (EAAT2) in astro- cytes enhances neuroprotection from moderate but not severe hypoxiaischemia. Neuroscience 155:1204-1211. CrossRef Medline

Wrathall JR, Choiniere D, Teng YD (1994) Dose-dependent reduction of tissue loss and functional impairment after spinal cord trauma with the AMPA/kainate antagonist NBQX. J Neurosci 14:6598-6607. Medline

Wright MC, Son YJ (2007) Ciliary neurotrophic factor is not required for terminal sprouting and compensatory reinnervation of neuromuscular synapses: re-evaluation of CNTF null mice. Exp Neurol 205:437-448. CrossRef Medline

Wu Y, Satkunendrarajah K, Teng Y, Chow DS, Buttigieg J, Fehlings MG (2013) Delayed post-injury administration of riluzole is neuroprotective in a preclinical rodent model of cervical spinal cord injury. J Neurotrauma 30:441-452. CrossRef Medline

Xu GY, Hughes MG, Ye Z, Hulsebosch CE, McAdoo DJ (2004) Concentrations of glutamate released following spinal cord injury kill oligodendrocytes in the spinal cord. Exp Neurol 187:329-336. CrossRef Medline

Xu GY, Liu S, Hughes MG, McAdoo DJ (2008) Glutamate-induced losses of oligodendrocytes and neurons and activation of caspase- 3 in the rat spinal cord. Neuroscience 153:1034-1047. CrossRef Medline

Yang Y, Gozen O, Watkins A, Lorenzini I, Lepore A, Gao Y, Vidensky S, Brennan J, Poulsen D, Won Park J, Li Jeon N, Robinson MB, Rothstein JD (2009) Presynaptic regulation of astroglial excitatory neurotransmitter transporter GLT1. Neuron 61:880-894. CrossRef Medline

Zolotukhin S, Byrne BJ, Mason E, Zolotukhin I, Potter M, Chesnut K, Summerford C, Samulski RJ, Muzyczka N (1999) Recombinant adenoassociated virus purification using novel methods improves infectious titer and yield. Gene Ther 6:973-985. CrossRef Medline 